\title{
Thermo-viscoplastic behaviour of 2024-T3 aluminium sheets subjected to low velocity perforation at different temperatures
}

\author{
J.A. Rodríguez-Martínez ${ }^{\mathrm{a}, *}$, A. Rusinek ${ }^{\mathrm{b}}$, A. Arias ${ }^{\text {a }}$ \\ a Department of Continuum Mechanics and Structural Analysis, University Carlos III of Madrid, Avda. de la Universidad 30, 28911 Leganés, Madrid, Spain

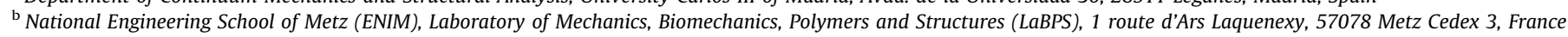

Keywords:

Aluminium alloy 2024-T3

Modified Rusinek-Klepaczko model

Perforation

Dynamic failure

\begin{abstract}
A B S T R A C T
This paper deals with the mechanical behaviour of the aluminium alloy 2024 T3.

particular relevance since it is widely used in the aeronautical industry for building aircraft structures. The deformation behaviour of this material has been characterised in tension under wide ranges of strain rate and temperature. Among the aluminium alloys, the AA 2024 T3 highlights due to its high flow stress and strain hardening. Moreover, the material temperature sensitivity has been found dependent on plastic strain. The Modified Rusinek Klepaczko constitutive description [Rusinek A, Rodríguez Martínez JA, Arias A. A thermo viscoplastic constitutive model for FCC metals with application to OFHC copper. Int. J. Mech. Sci. 52 (2010) 120 135], which takes into account such dependence of the temperature sensitivity on plastic strain, has been applied for modelling the thermo viscoplastic response of the material. Satisfactory agreement between experiments and analytical predictions provided by the Modified Rusinek Klepaczko model has been found. In order to study the material behaviour under impact loading, low velocity perforation tests on AA 2024 T3 sheets have been performed at different initial temperatures using a drop weight tower. Plastic instabilities formation and progression are identified as the cause behind the target collapse for all the impact tests conducted. The results from these perforation tests are compared with those reported in [Rodríguez Martínez JA, Pesci R, Rusinek A, Arias A, Zaera R, Pedroche DA. Thermo mechanical behaviour of TRIP 1000 steel sheets subjected to low velocity perforation by conical projectiles at different temperatures. Int. J. Solids Struct. 47 (2010) 1268 1284.] for TRIP 1000 steel sheets. The comparison reveals that the amount of specific energy absorbed by the aluminium targets is much lower than that corresponding to the steel targets. The role played by inertia on delaying plastic instabilities formation is determined as potential responsible for such behaviour.
\end{abstract}

\section{Introduction}

Structural impact has become increasingly relevant for numer ous engineering fields like aeronautical, naval or automotive industry. Among the materials traditionally investigated for building protection structures responsible for energy absorption in high loading rate events, the light weight alloys have particular interest. A considerably amount of scientific works has been published over the last decades dealing with the mechanical response of magnesium, titanium and aluminium alloys subjected to impact loading [ 11 7].

Those investigations answer to the requirements of the pre viously mentioned industrial sectors of replacing traditional steel alloys by such metallic materials with improved strength to weight ratio [5 8]. In particular, aluminium alloys are being widely introduced for building automobile and aircraft structures. This

\footnotetext{
* Corresponding author. Tel.: +34 91624 8809; fax: +34916249430.

E-mail address: jarmarti@ing.uc3m.es (J.A. Rodríguez-Martínez).
}

trend is enhanced by the key factor which represents fuel economy in design stages.

Among the impact events on aluminium structures, perforation processes have gathered the efforts of many researchers [9 12$]$. The works due to Borvik and co workers [13 16] and Gupta and co workers [17 21] are distinguished by their relevance in this field. In those works the response of aluminium plates subjected to perforation by non deformable projectiles is comprehensively approached. The attention was mainly focused on two different aspects: providing an accurate description of the thermo visco plastic behaviour of the material and determination of the deformation mechanisms involved in the process of energy absorption during perforation.

In the present investigation is made common cause with those purposes and the attention is focused on the mechanical behaviour of the aluminium alloy (AA) 2024-T3. This metal is widely applied in the aeronautical industry for construction of mechanical elements with elevated structural responsibility. The thermo mechanical behaviour of the material is characterised in tension under wide ranges of strain rate and temperature. 
Its thermo viscoplastic response under loading has been modelled by means of the Modified Rusinek Klepaczko (MRK) constitutive description [22]. Such physical based model allows gathering the influence that plastic strain has on the rate sensitivity of this material. Satisfactory agreement between experiments and analy tical predictions of the MRK model is found. This physical based modelling of the material behaviour constitutes an improvement with respect to the purely phenomenological descriptions com monly applied in the literature for prediction of aluminium alloys response under dynamic solicitations [16,20 21,23].

Moreover, the impact/perforation behaviour of this alloy is examined. Low velocity perforation tests on AA 2024-T3 sheets are conducted at different initial temperatures using a drop weight tower. The process of strain localisation and subsequent plastic instabilities progression are determined responsible for the target collapse in all the impact tests conducted. The results obtained from these perforation tests are compared with those reported by Rodríguez Martínez et al. [24] for TRIP 1000 steel sheets. The comparison reveals that the amount of specific energy absorbed by the aluminium targets is much lower than that corresponding to the steel targets. The role played by inertia on delaying plastic instabilities formation is determined as potential responsible for such behaviour. The research conducted shows the necessity to assess the suitability of certain light weight alloys for absorbing energy in dynamic events involving instabilities and failure.

\section{Experimental characterisation of the thermo-viscoplastic behaviour of the AA 2024-T3}

The AA 2024-T3 is an aluminium alloy, with $\mathbf{C u}$ and $\mathbf{M g}$ as the main alloying elements. The chemical composition of the material (\% of weight) is reported in Table 1.

It shows good machinability and surface finish capabilities. It is a high strength aluminium alloy of adequate workability. It is widely used in aircraft structures where stiffness, fatigue performance and good strength are required. Other applications comprise hydraulic valve bodies, missile parts, munitions, nuts or pistons.

The thermo viscoplastic behaviour of the material has been characterised in tension under wide ranges of strain rate $0.001 \mathrm{~s}^{-1} \leq \dot{\varepsilon} \leq 200 \mathrm{~s}^{-1}$ and temperature $223 \mathrm{~K} \leq T_{0} \leq 373 \mathrm{~K}$. The geometry and dimensions of the tensile specimens used in the characterisation are depicted in Fig. 1.

In Fig. 2, the material flow stress evolution as a function of strain at low strain rates and room temperature is shown. Among

Table 1

Chemical composition of the AA 2024-T3 (\% of weight).

\begin{tabular}{llllllll}
\hline Mn & Si & Cr & Ti & Fe & Mg & Zn & Cu \\
\hline 0.6 & 0.5 & 0.1 & 0.15 & 0.5 & 1.5 & 0.25 & 4.3 \\
\hline
\end{tabular}

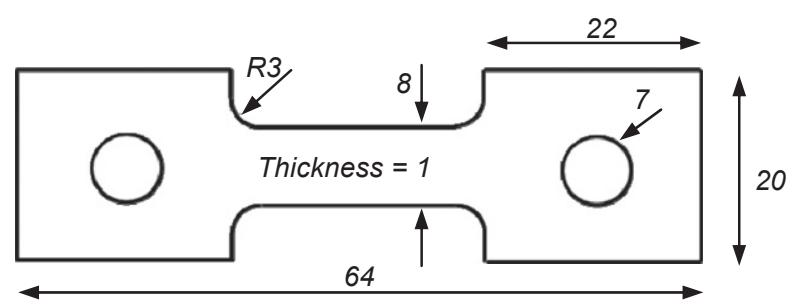

Fig. 1. Geometry and dimensions of the tensile specimens used for the mechanical characterisation of the material at low and high strain rates ( $\mathrm{mm}$ ).

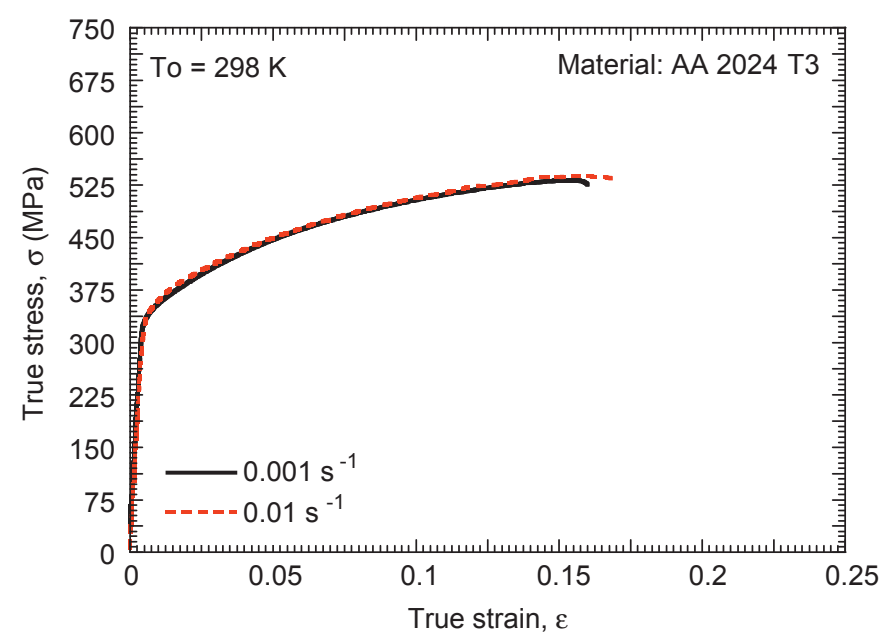

Fig. 2. Flow stress evolution versus strain for different low strain rates at room temperature.

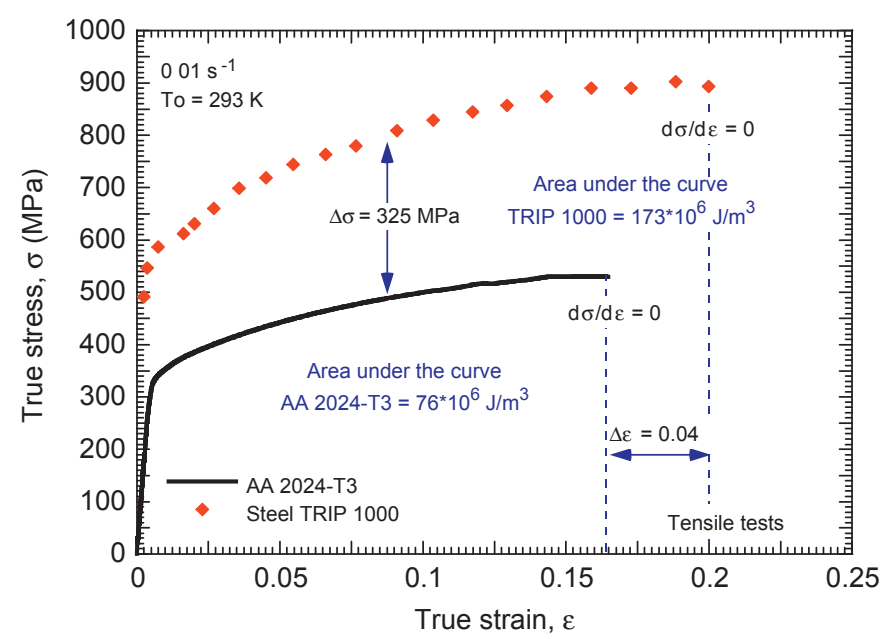

Fig. 3. Flow stress evolution as a function of strain at low strain rate and room temperature. Comparison between AA 2024-T3 and steel TRIP 1000 [25].

the aluminium alloys, the AA 2024-T3 highlights due to its high flow stress and hardening rate which enhances its capability for absorbing energy in loading processes, Fig. 2.

Those characteristics are clearly noticed when the mechanical behaviour of the AA 2024-T3 is compared, for example, with that corresponding to a High Strength Steel like TRIP 1000, Fig. 3. The comparison with the steel TRIP $\mathbf{1 0 0 0}$ is justified since, later on, perforation tests conducted on both materials will be compared. The tensile specimens used for characterisation of the mechanical behaviour of the TRIP $\mathbf{1 0 0 0}$ [25] also answer to the geometry and dimensions illustrated in Fig. 1.

Bearing in mind that the density of aluminium is lower than that of steel $\rho_{\text {AA2024-T3 }} / \rho_{\text {TRIP 1000 }} \approx 0.35$ (where $\rho_{\text {AA2024-T3 }}=$ $2700 \mathrm{~kg} / \mathrm{m}^{3}$ and $\rho_{\text {TRIP } 1000}=7800 \mathrm{~kg} / \mathrm{m}^{3}$ ); it has been observed that, comparatively, the AA 2024-T3 displays remarkable ratios of flow stress $\left.\sigma\right|_{\dot{\varepsilon}, T} ^{\mathrm{AA} 2024-\mathrm{T} 3} /\left.\sigma\right|_{\dot{\varepsilon}, T} ^{\mathrm{TRIP}} 1000 \approx 0.65$, hardening rate $\partial \sigma /\left.\partial \varepsilon^{p}\right|_{\dot{\varepsilon}, T} ^{\mathrm{AA} 2024-\mathrm{T} 3} / \partial \sigma /\left.\partial \varepsilon^{p}\right|_{\dot{\varepsilon}, T} ^{\mathrm{TRIP}} 1000 \approx 1$ and ductility $\varepsilon_{\text {failure }}$ $\left.\right|_{\dot{\varepsilon}, T} ^{\text {AA } 2024-T 3} /\left.\varepsilon_{\text {failure }}\right|_{\dot{\varepsilon}, T} ^{\text {TRIP } 1000} \approx 0.8$, Fig. 3 .

Moreover, let us calculate the energy per unit volume absorbed by both metals in the tests reported in Fig. 3. This corresponds to 


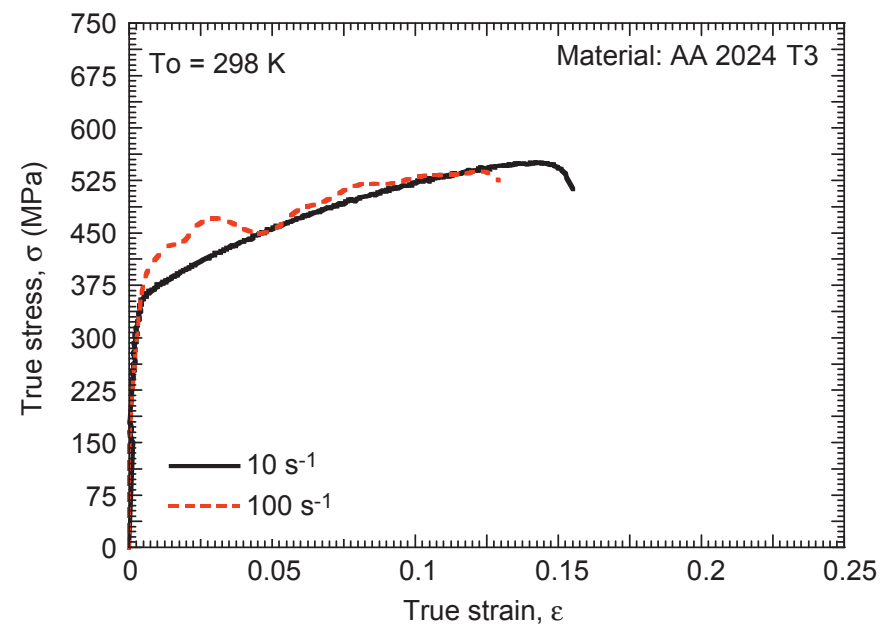

Fig. 4. Flow stress evolution versus strain for different strain rates at room temperature.

the area under the stress strain curve (full integral)

$E_{V}=\int_{0}^{\varepsilon_{\text {failure }}} \sigma d \varepsilon$

It has been found that, at failure $\varepsilon_{\text {failure }}=\left.\varepsilon\right|_{d \sigma / d \varepsilon \quad} \quad{ }_{0}$, the TRIP 1000 steel absorbs quite larger amount of energy per unit volume than the AA 2024-T3, $E_{V}^{\mathrm{TRIP} 1000}=173 \times 10^{6} \mathrm{~J} / \mathrm{m}^{3}>E_{V}^{\mathrm{AA} 2024-\mathrm{T} 3}=$ $76 \times 10^{6} \mathrm{~J} / \mathrm{m}^{3}$.

At this point, it is necessary to introduce the concept of specific energy, $E_{\mathrm{S}}$, which is defined as the energy absorbed by the material per unit mass [26 27]. The specific energy allows conducting a proper comparison of the capacity for energy absorption of materials having different densities. Dividing the energy per unit volume previously reported, Eq. (1), by the corresponding material density; the following results are obtained

$\left\{\begin{array}{l}E_{\mathrm{S}}^{\mathrm{TRIP} 1000}=\frac{E_{\mathrm{V}}^{\mathrm{TRPP} 1000}}{\rho_{\text {TRIP } 1000}}=22.2 \times 10^{3} \mathrm{~J} / \mathrm{kg} \\ E_{\mathrm{S}}^{\mathrm{AAA} 2024-\mathrm{T} 3}=\frac{E_{\mathrm{V}}^{\mathrm{AA} 2024 \mathrm{T3}}}{\rho_{\text {AA } 2024 \mathrm{T3}}}=28.1 \times 10^{3} \mathrm{~J} / \mathrm{kg}\end{array}\right.$

The results shown in the above expression, Eq. (2), illustrate that, at failure, the specific energy absorption in the case of the aluminium alloy is slightly greater. From these results it could be expected that the AA 2024-T3 will show superior ability than the TRIP 1000 steel for specific energy absorption under impact events. This point will be matter of discussion in following sections of this paper.

Next, the flow stress of the AA 2024-T3 as a function of strain under different high loading rates at room temperature is shown, Fig. 4. It has to be highlighted that the material strain hardening is not being reduced with the deformation rate increase, Fig. 4. It seems that thermal softening does not play an important role on the material behaviour within the range of strain rates tested.

Moreover, in Fig. 5 is illustrated the flow stress evolution versus strain rate for different plastic strain values. The AA 2024-T3 shows quite reduced and almost linear rate sensitivity within the range of strain rates tested (it was reported in [25] that the TRIP 1000 also shows quite reduced rate sensitivity). Such behaviour is in agreement with the observations reported in several works [1,7,22,28 29] for FCC metals.

A remarkable characteristic of this alloy is the increase of its strain hardening with the temperature decrease, Fig. 6 . It means that the temperature sensitivity is dependent on plastic strain (and therefore the Volume Thermally Activated is dependent on plastic strain). Because of that, the ductility of the material seems to be improved at low initial temperatures (within the range of

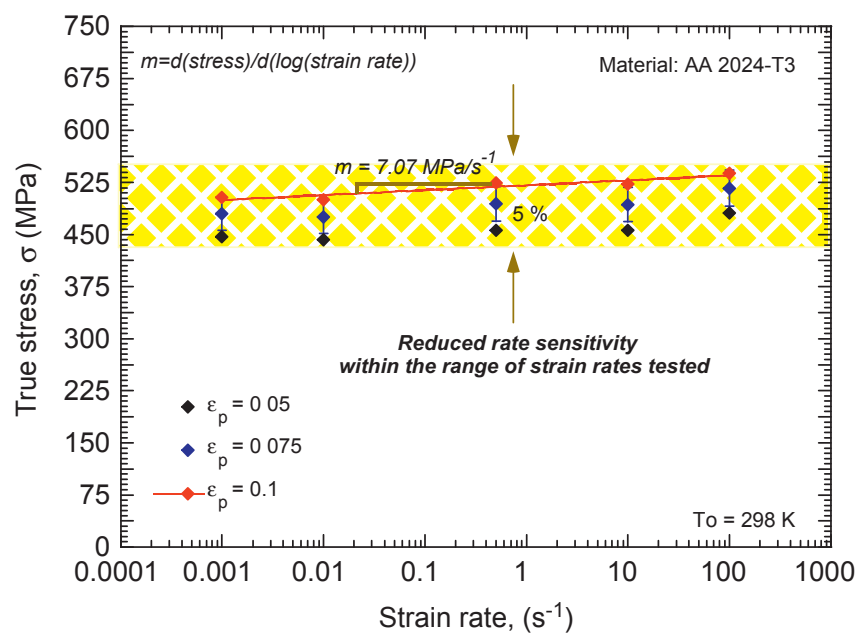

Fig. 5. Flow stress evolution versus strain rate for different plastic strain levels.

temperatures considered in this work), Fig. 6. It is obvious that such behaviour makes this alloy suitable for aeronautical applications in which the service temperature is usually within the range $213 \mathrm{~K} \leq T_{0} \leq 293 \mathrm{~K}$.

Based on previous considerations, the thermo viscoplastic behaviour of the AA 2024-T3 is modelled using the MRK con stitutive relation [22]. This constitutive description takes into account the effect of plastic strain on the Volume Thermally Activated of the material.

\section{Modelling of the thermo-viscoplastic behaviour of the AA 2024-T3}

Next, the formulation of the MRK model is introduced. In addition, the comparison of its analytical predictions with experi mental results is reported.

\subsection{The Modified Rusinek Klepaczko model}

The MRK constitutive relation is based on the additive decom position of the Huber Mises equivalent stress [30 35]

$\bar{\sigma}\left(\bar{\varepsilon}^{p}, \dot{\bar{\varepsilon}}^{p}, T\right)=\frac{E(T)}{E_{0}}\left[\bar{\sigma}_{\mu}+\bar{\sigma}^{*}\left(\bar{\varepsilon}^{p}, \dot{\bar{\varepsilon}}^{p}, T\right)\right]$

where each term of previous expression, Eq. (3), is defined below.

The multiplicative factor $E(T) / E_{0}$ defines the Young's modulus evolution with temperature [36]

$E(T)=E_{0}\left\{1 \frac{T}{T_{\mathrm{m}}} \exp \left[\theta^{*}\left(1 \frac{T_{\mathrm{m}}}{T}\right)\right]\right\}, \quad T>0$

where $E_{0}, \quad T_{\mathrm{m}}$ and $\theta^{*}$ denote, respectively, the Young's modulus at $T=0 \mathrm{~K}$, the melting temperature and the characteristic homo logous temperature. This expression allows for defining the material thermal softening depending on the crystal lattice [37]. In the case of FCC metals like aluminium alloys, $\theta^{*} \approx 0.9$, as discussed in [7 37].

According to the considerations for FCC metals reported in [31,38 39], the athermal stress $\bar{\sigma}_{\mu}$ is assumed independent of plastic strain. In agreement with [40] this stress component is defined as follows

$\bar{\sigma}_{\mu}=Y$

where $Y$ is the flow stress at $\bar{\varepsilon}^{p}=0$. 
The thermal stress $\bar{\sigma}^{*}$ is the flow stress component defining macroscopically the rate dependent interactions with short range obstacles. It denotes the rate controlling deformation mechanism from thermal activation. Based on the theory of thermodynamics and kinetics of slip [41], Rusinek et al. [22] derived the following expression:

$\bar{\sigma}^{*}\left(\bar{\varepsilon}^{p}, \dot{\bar{\varepsilon}}^{p}, T\right)=B\left(\dot{\bar{\varepsilon}}^{p}, T\right) \cdot\left(\bar{\varepsilon}^{p}\right)^{n\left(\dot{\bar{\varepsilon}}^{p}, T\right)} \cdot\left\langle 1 \quad \xi_{1}\left(\frac{T}{T_{m}}\right) \log \left(\frac{\dot{\varepsilon}_{\max }}{\dot{\bar{\varepsilon}}^{p}}\right)\right\rangle^{1 / \xi_{2}}$

where $\xi_{1}$ and $\xi_{2}$ are material constants describing temperature and rate sensitivities of the material, $T_{\mathrm{m}}$ is the melting tempera ture and $\dot{\varepsilon}_{\max }$ is the upper limit of deformation rate taken as reference (frequency factor [42]).

The explicit formulations describing the modulus of plasticity $B\left(\dot{\bar{\varepsilon}}^{p}, T\right)$ and the strain hardening exponent $n\left(\dot{\bar{\varepsilon}}^{p}, T\right)$ are given by the following equations:

$B\left(\dot{\bar{\varepsilon}}^{p}, T\right)=B_{0}\left(\left(\frac{T}{T_{m}}\right) \log \left(\frac{\dot{\varepsilon}_{\max }}{\dot{\bar{\varepsilon}}^{p}}\right)\right)^{-v}, \quad T>0$

a
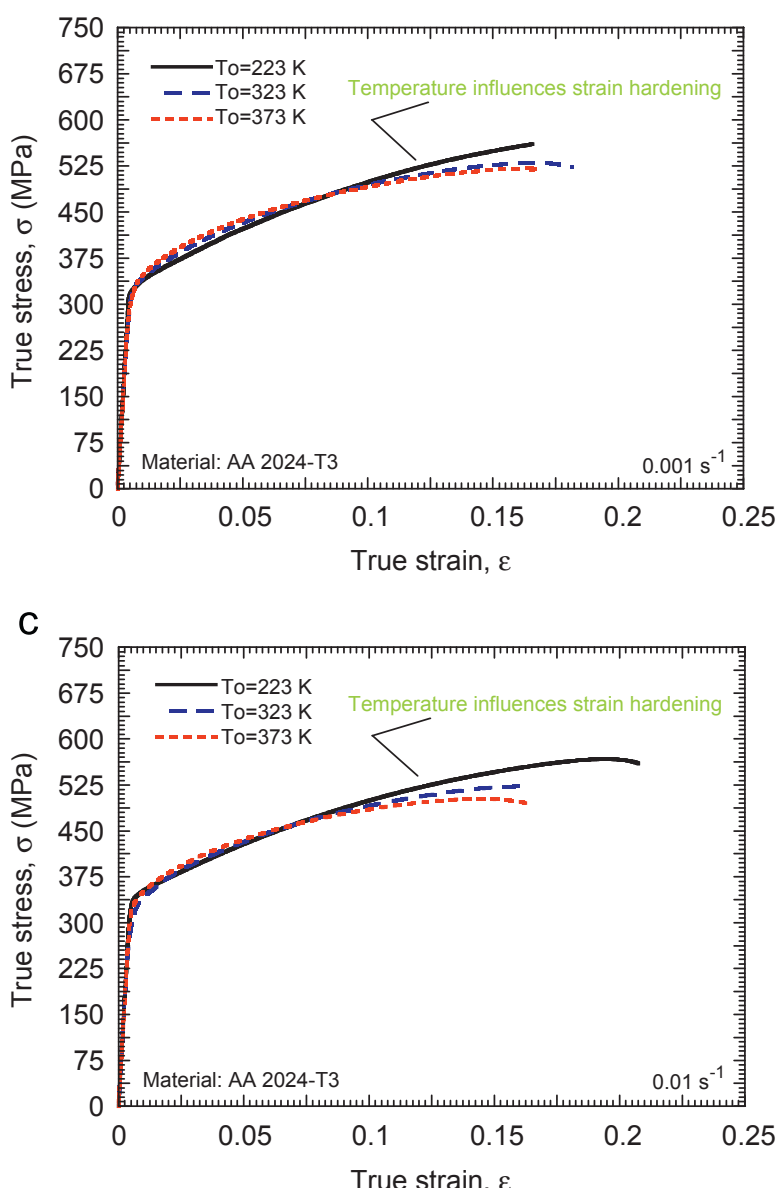

$n\left(\dot{\bar{\varepsilon}}^{p}, T\right)=n_{0}\left\langle 1 \quad D_{2}\left(\frac{T}{T_{m}}\right) \log \left(\frac{\dot{\bar{\varepsilon}}^{p}}{\dot{\varepsilon}_{\min }}\right)\right\rangle$

where $B_{0}$ is a material constant, $v$ is proportional to temperature sensitivity, $n_{0}$ is the strain hardening exponent at $T=0 \mathrm{~K}, D_{2}$ is a material constant and $\dot{\varepsilon}_{\text {min }}$ is the minimum rate level for applica tion of the model. The McCauley operator is defined as follows $\langle\bullet\rangle=\bullet$ if $\langle\bullet\rangle \geq 0$ or $\langle\bullet\rangle=0$ if $\langle\bullet\rangle \leq 0$.

In the case of adiabatic conditions of deformation the consti tutive relation is combined with the energy balance principle, Eq. (9). Such relation allows for an approximation of the thermal softening of the material via the adiabatic heating [43]

$\Delta T\left(\bar{\varepsilon}^{p}, \bar{\sigma}\right)=\frac{\beta}{\rho C_{p}} \int_{0}^{\bar{\varepsilon}_{\max }^{p}} \bar{\sigma}\left(\bar{\varepsilon}^{p}, \dot{\bar{\varepsilon}}^{p}, T\right) d \bar{\varepsilon}^{p}$

where $\beta$ is the Taylor Quinney coefficient assumed as constant, $\rho$ is the material density and $C_{p}$ is the specific heat at constant pressure. Transition from isothermal to adiabatic conditions of deformation is assumed at $\dot{\bar{\varepsilon}}^{p}=10 \mathrm{~s}^{-1}$ in agreement with experimental observations

b

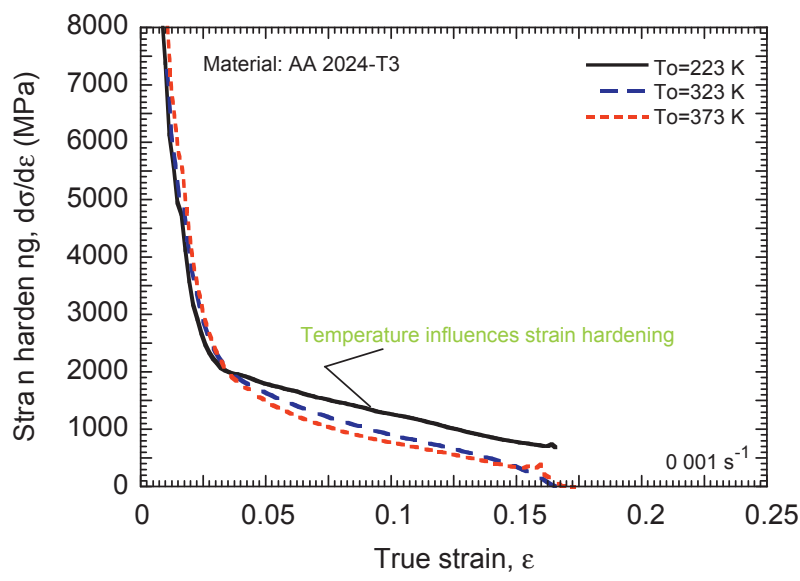

d

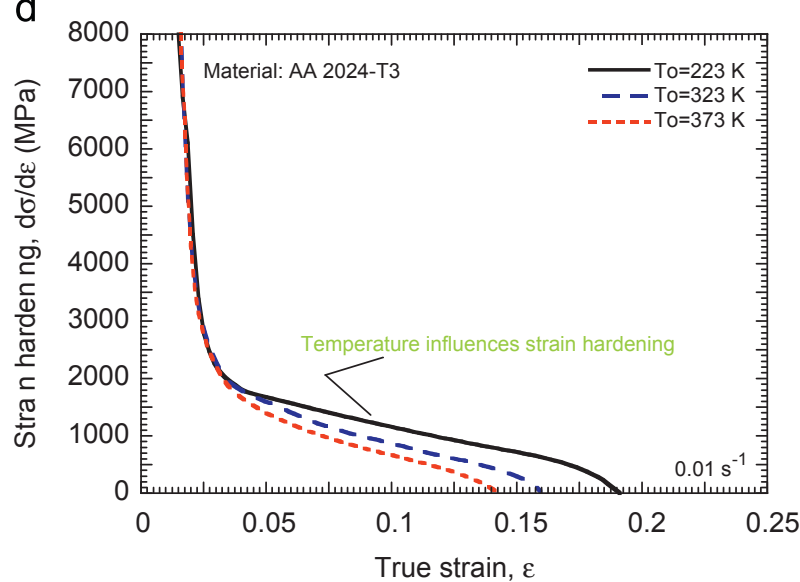

Fig. 6. (a)-(c) Flow stress evolution versus strain for different strain rates and initial temperatures. (b)-(d) Strain hardening evolution versus strain for different strain rates and initial temperatures.

Table 2

Constants determined for calibration of the MRK model for AA 2024-T3.

\begin{tabular}{|c|c|c|c|c|c|c|c|c|c|c|}
\hline $\mathrm{Y}(\mathrm{MPa})$ & $B_{0}(\mathrm{MPa})$ & $v(-)$ & $n_{0}(-)$ & $D_{2}(-)$ & $\xi_{2}(-)$ & $\xi_{1}(-)$ & $T_{m}(\mathrm{~K})$ & $\varepsilon_{\min }\left(\mathrm{s}^{1}\right)$ & $\varepsilon_{\max }\left(\mathrm{s}^{1}\right)$ & $\theta^{*}(-)$ \\
\hline 300 & 1000.2 & 0.07023 & 0.4805 & 0.0292 & 0.00845 & 0.001159 & 900 & $10^{5}$ & $10^{7}$ & 0.9 \\
\hline
\end{tabular}


and numerical estimations for metals and alloys reported for example in [44 45].

Next, the MRK model is applied to describe the thermo viscoplastic behaviour of the AA 2024-T3.

\subsection{Application of the Modified Rusinek Klepaczko model to describe the thermo viscoplastic behaviour of the AA 2024 T3}

The material constants corresponding to the AA 2024-T3 are listed in Table 2 . They were obtained via a systematic procedure for calibration of the model [22]. This procedure ensures the uniqueness of their values [22].

Conventional physical constants of aluminium may be obtained from material handbooks, Table 3.

Next, the predictions of the constitutive model are compared with experiments. In Fig. 7. is observed that the model describes properly the material flow stress and strain hardening from low to high loading rates at room temperature.

Moreover, the rate sensitivity of the material is also well defined by the model as illustrated in Fig. 8 for different values of plastic deformation.

Table 3

Physical constants for aluminium.

\begin{tabular}{llll}
\hline$E_{0}(\mathrm{GPa})$ & $C_{p}\left(\mathrm{~J} \mathrm{~kg}^{1} \mathrm{~K}^{1}\right)$ & $\beta(-)$ & $\rho\left(\mathrm{kg} \mathrm{m}^{3}\right)$ \\
\hline 70 & 920 & 0.9 & 2700 \\
\hline
\end{tabular}

It is remarkable that the model is suitable for describing the strain hardening variations due to initial temperature effect, Fig. 9. As previously mentioned, this fact is of main relevance for aeronautical applications where this alloy is widely used.

Up to now, mechanical characterisation and analytical modelling of the AA 2024-T3 have provided the keys of the thermo viscoplastic

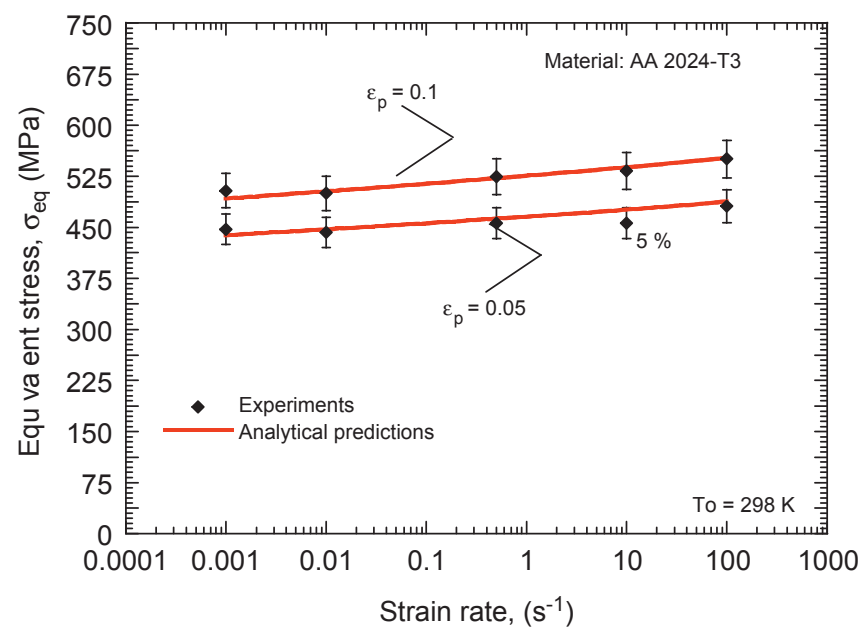

Fig. 8. Flow stress evolution as a function of strain rate at room temperature for different plastic strain levels and comparison with analytical predictions of the MRK model.

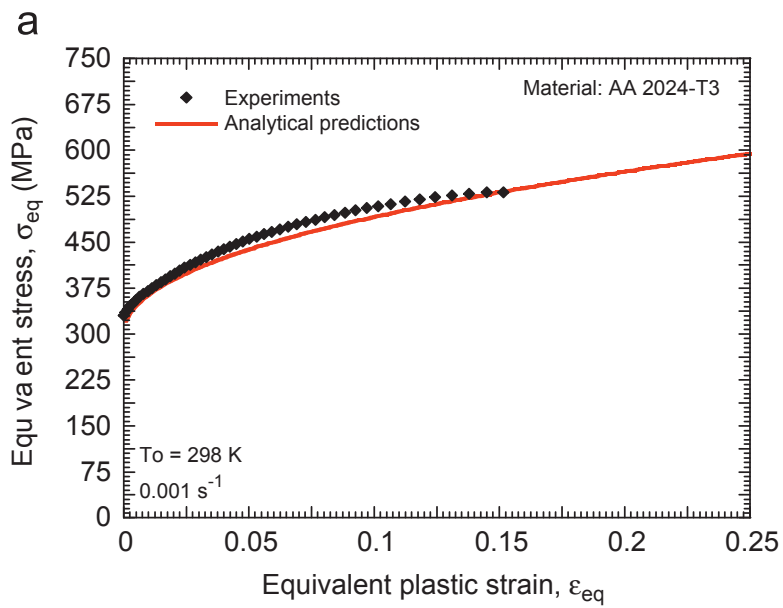

b
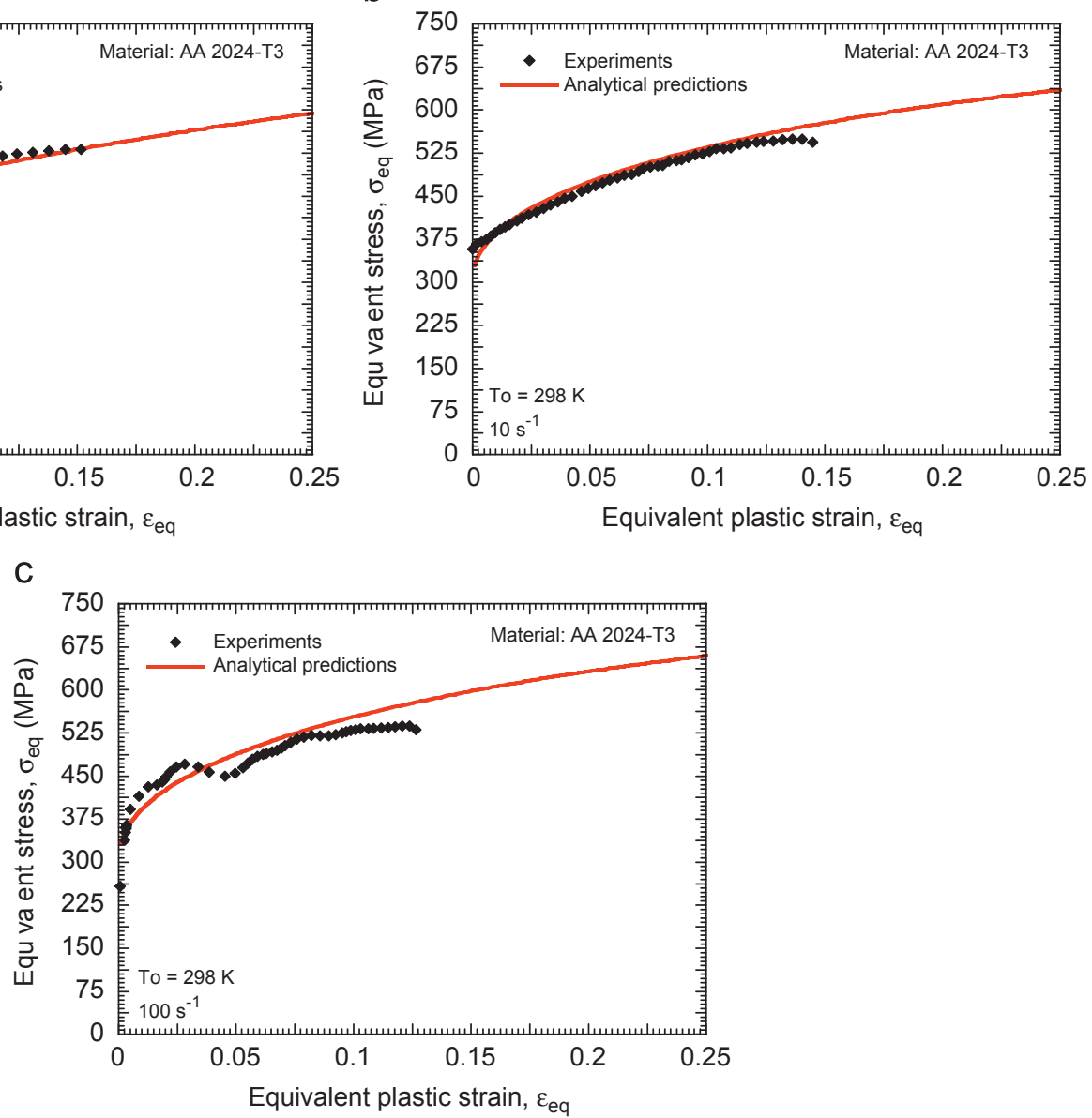

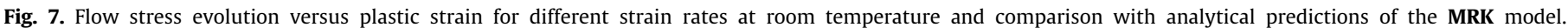
(a) $0.001 \mathrm{~s}^{1}$, (b) $10 \mathrm{~s}^{1}$, (c) $100 \mathrm{~s}^{1}$. 
response of this material. Next, and based on this understanding of the material behaviour, low velocity perforation tests on AA 2024-T3 sheets are performed. The analysis will allow for evaluation of the suitability of this alloy for absorbing energy under dynamic loading. Such methodology, mechanical characterisation thermo viscoplas tic analysis Impact/perforation testing, has been applied in relevant publications [13 14,16 17].

\section{Low velocity perforation of AA 2024-T3 sheets at different temperatures}

In this section of the manuscript the experimental setup applied for perforation of the aluminium sheets is introduced and the results obtained from the tests are discussed. The analysis considers (and relates) impact velocity, specific energy absorbed by the plates, failure mode, evolution of the impact force versus striker displacement and testing temperature. The effect of some of these parameters on the perforation of metallic sheets has been rarely studied, especially the influence of initial temperature was not studied in detail, mainly due to the complex experimental devices required for highly instrumented tests.

\subsection{Experimental setup for low velocity perforation of metallic sheets: the drop weight tower}

In order to conduct the perforation tests a drop weight tower has been used. This experimental arrangement was applied by Rodríguez Martínez et al. [24] for low velocity perforation of

a

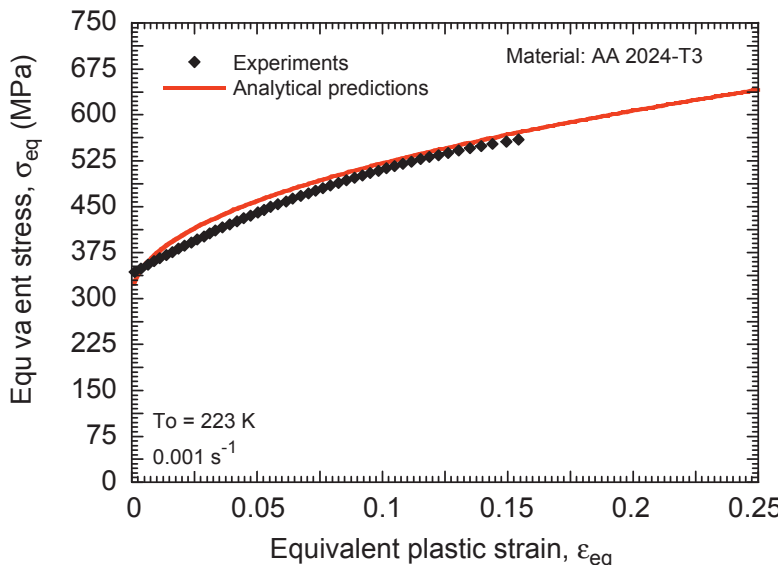

C

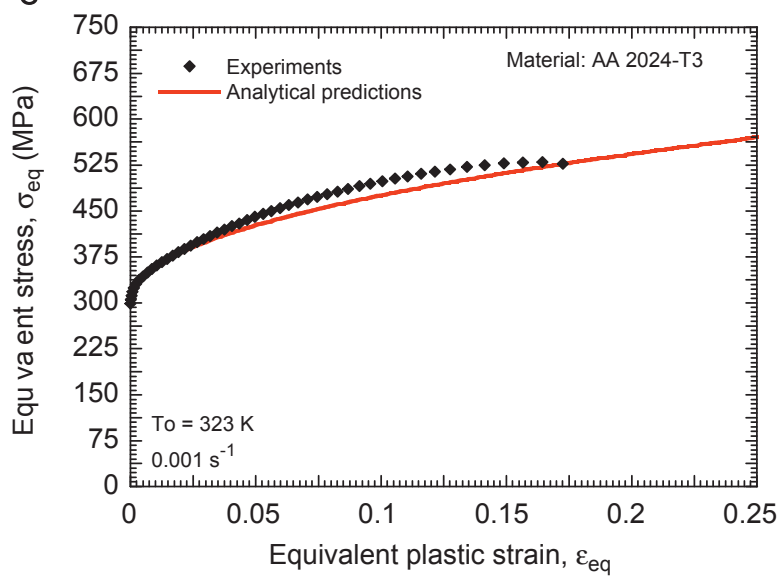

TRIP 1000 steel sheets. Thus, in this section of the manuscript let us simply provide the main features of the experimental setup, details can be found in the work cited above.

This experimental configuration allows a perpendicular impact on the aluminium sheets within the range of impact velocities $0.5 \mathrm{~m} / \mathrm{s} \leq V_{0} \leq 4.5 \mathrm{~m} / \mathrm{s}$. The impact velocity $V_{0}$ is fixed by the user by choosing the height from which the striker is dropped $h_{0}$

$V_{0}=\sqrt{ } 2 g h_{0}$

where $g$ is the gravity.

The drop weight tower has a climatic chamber allowing variations in the testing temperature. Two different initial tem peratures were applied in the experiments, $T_{0}=213$ and $288 \mathrm{~K}$, respectively.

The tested square like specimens possess a size of $A_{t}=100 \times$ $100 \mathrm{~mm}^{2}$ and a thickness of $h=1 \mathrm{~mm}$. They were clamped by screws all around the active surface of $A_{f}=80 \times 80 \mathrm{~mm}^{2}$. The screws were symmetrically fixed in order to avoid any distur bance during the test. The device used to clamp the aluminium sheets had a transparent side made of PMMA. Such an arrange ment allowed filming the perforation process using a high speed camera.

The steel striker used has a conical shape as shown in Fig. 10. Its larger diameter is $\varphi_{p}=20 \mathrm{~mm}$ and its mass is $M_{p}=0.105 \mathrm{~kg}$. After machining the striker was oil quenched; it permitted to avoid its damage or erosion during perforation, Fig. 10.

The striker was attached to the instrumented bar of the drop weight tower, whose mass is $M_{\mathrm{bar}}=0.761 \mathrm{~kg}$. Additional mass was added to the setup in order to increase the effective mass

b

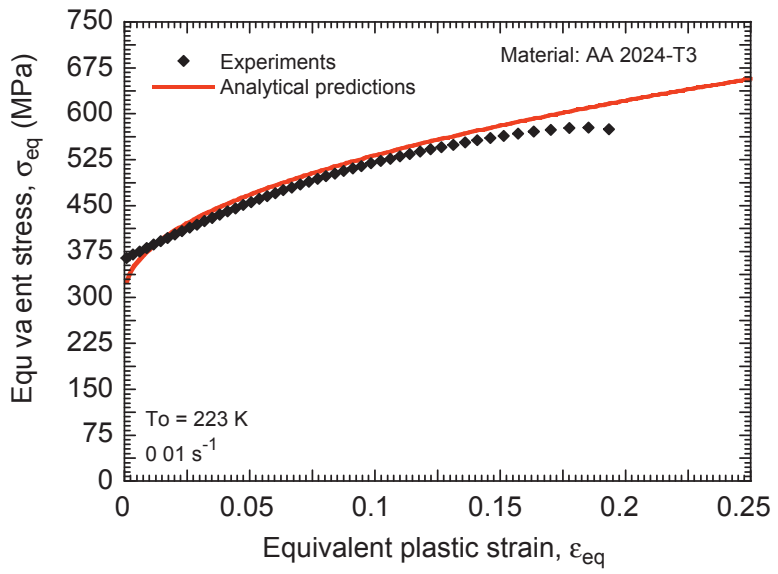

d

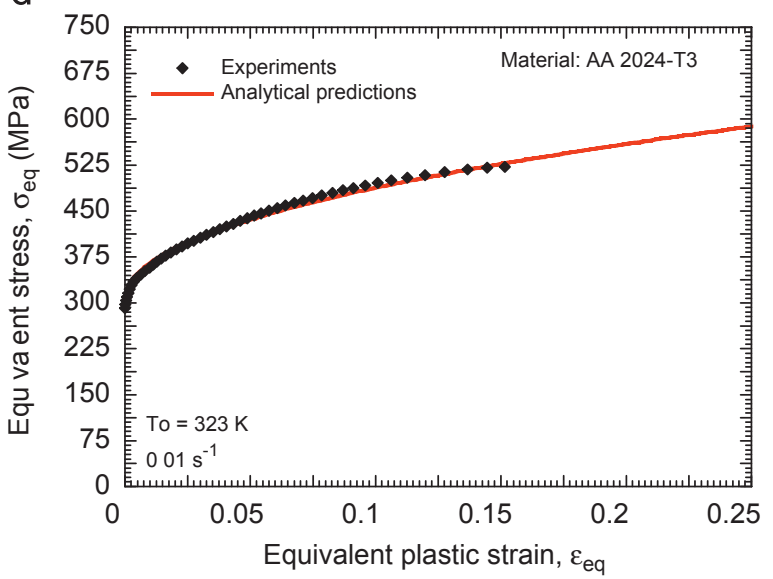

Fig. 9. Flow stress evolution versus strain for different strain rates and temperatures and comparison with analytical predictions of the MRK model. 
to $M_{\text {total }}=18.787 \mathrm{~kg}$ (The range of the impact energy covers $2.35 \mathrm{~J} \leq E_{i} \leq 190 \mathrm{~J}$ ). A load cell placed on the striker enabled to record the impact force versus time signal. The force cell records 4000 measurements, which are equally spaced within the acqui sition time. For all the tests conducted the acquisition time was set to 16 ms leading to an acquisition frequency of $250 \mathrm{kHz}$. This high acquisition frequency allows for an accurate definition of the force evolution as a function of time. The time dependent velocity $V(t)$ and displacement $\delta_{\mathrm{s}}(t)$ of the striker during perfora tion may be calculated by integration of the impact force versus time curve $F(t)$

$F(t)=M_{\text {total }}[a(t)+g] ; \quad a(t)=\frac{F(t) M_{\text {total }} g}{M_{\text {total }}}$

$$
\begin{aligned}
& V(t)=V_{0} \quad \int_{0}^{t} \frac{F(t) M_{\text {total }} g}{M_{\text {total }}} d t \\
& \delta_{s}(t)=\int_{0}^{t}\left[\begin{array}{lll}
V_{0} & \left.\int_{0}^{t} \frac{F(t) M_{\text {total }} g}{M_{\text {total }}} d t\right] d t
\end{array}\right.
\end{aligned}
$$

where $a(t)$ is the deceleration of the striker during perforation.

Next, the low velocity impact behaviour of the AA 2024-T3 samples is analysed. The results obtained for the impacted AA 2024-T3 sheets are compared with those corresponding to TRIP 1000 steel sheets published by Rodríguez Martínez et al. [24]. The AA 2024-T3 and the TRIP 1000 samples have the same size and thickness; in addition the experimental arrangement applied for
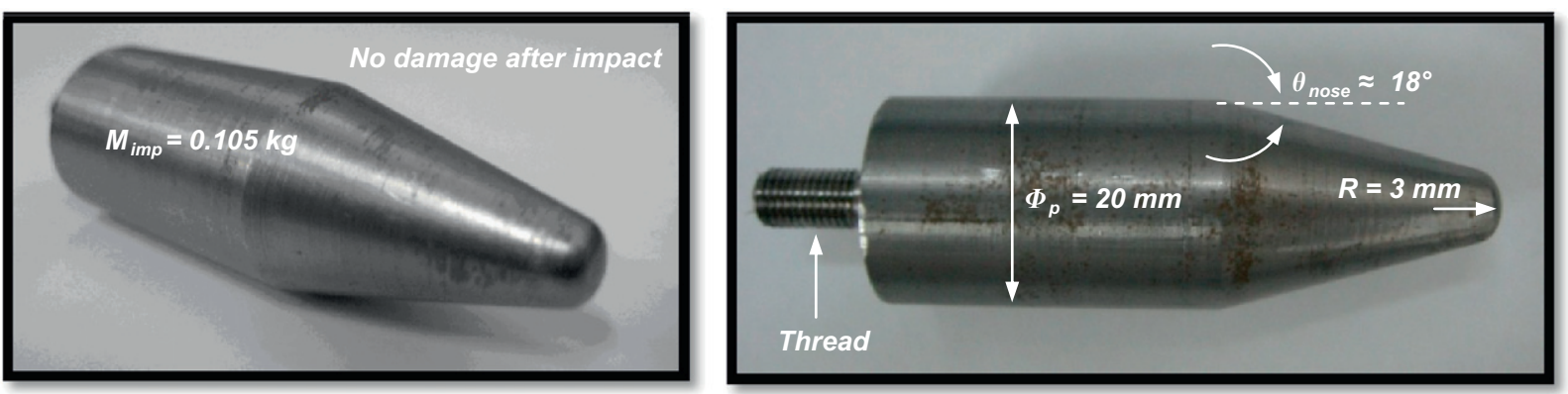

Fig. 10. Conical striker used in the drop weight tower tests.

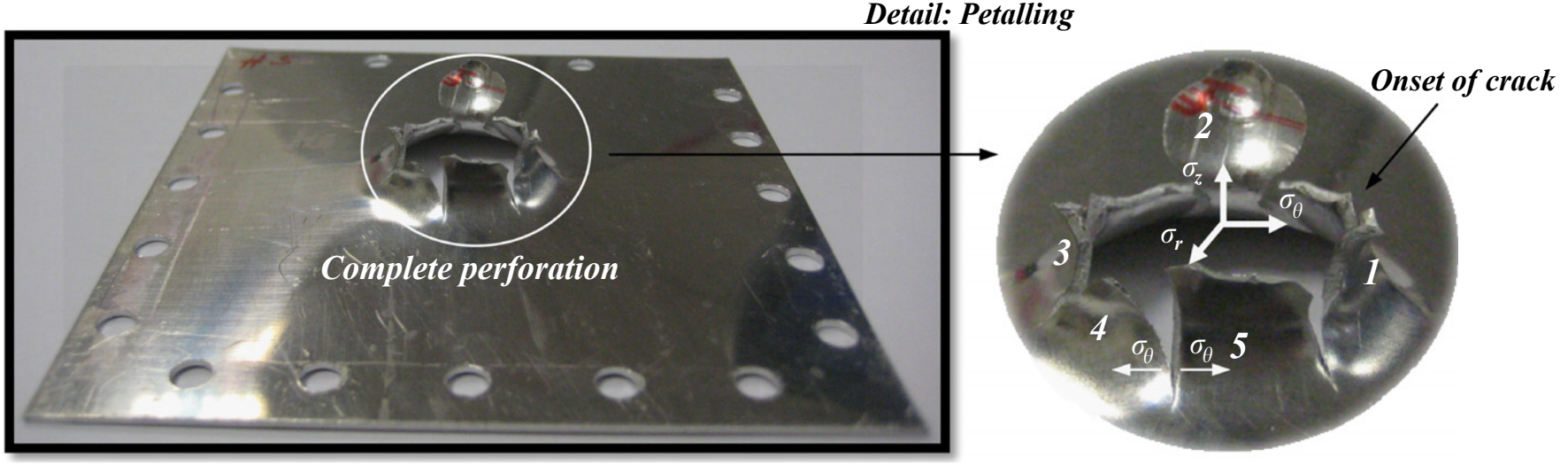

Fig. 11. Petalling failure mode for an AA 2024-T3 sheet impacted at $V_{0} \quad 2.0 \mathrm{~m} / \mathrm{s}$ and $T_{0} \quad 288 \mathrm{~K}$.

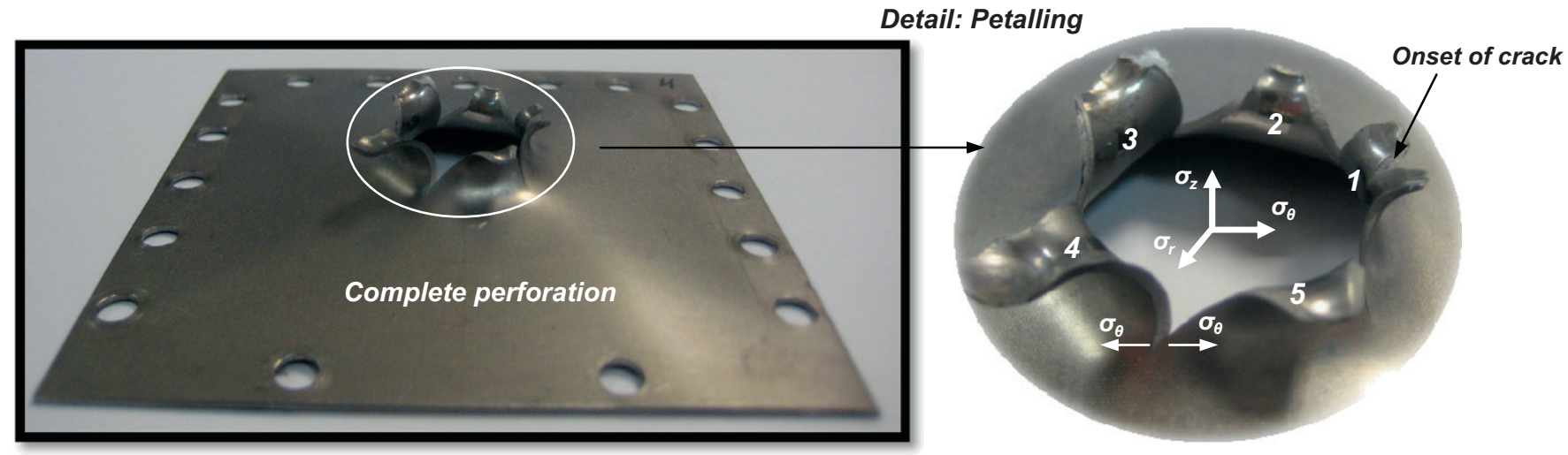

Fig. 12. Petalling failure mode for a TRIP 1000 steel sheet impacted at $V_{0} \quad 4.4 \mathrm{~m} / \mathrm{s}$ and $T_{0} \quad 288 \mathrm{~K}$ [24]. 
$A A$ 2024- $T 3-V_{0}=4.0 \mathrm{~m} / \mathrm{s}$
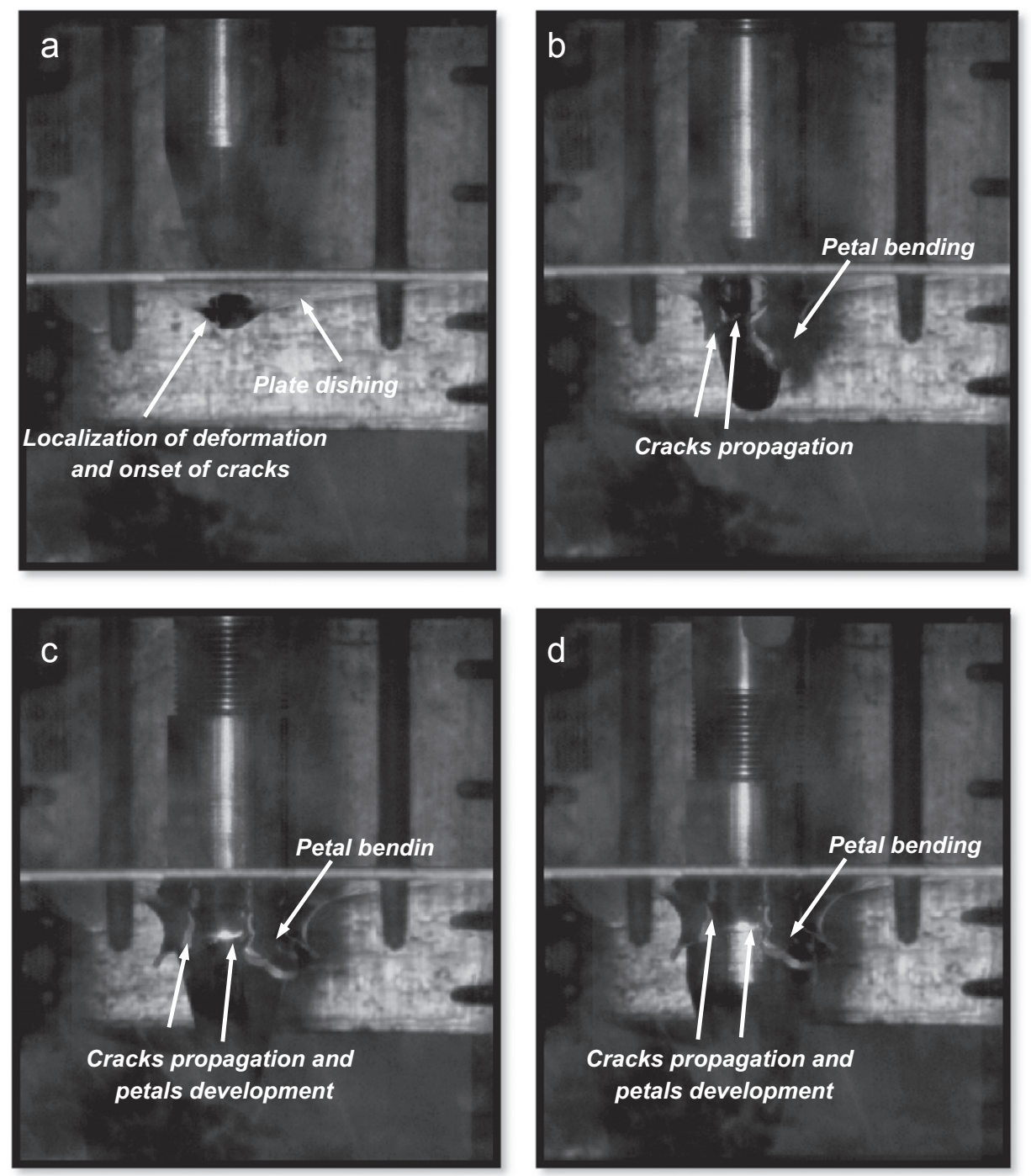

Fig. 13. Different stages of the perforation process for an AA 2024-T3 sheet, $V_{0} \quad 4.0 \mathrm{~m} / \mathrm{s}$ and $T_{0} \quad 288 \mathrm{~K}$. (a) Localisation of deformation and onset of cracks. (b) Cracks progression and formation of petals. (c) Development and bending of petals. (d) Complete passage of the impactor and petalling failure mode. Acquisition frequency: 15000 fps. Picture resolution: $640 \times 480$ pixels.
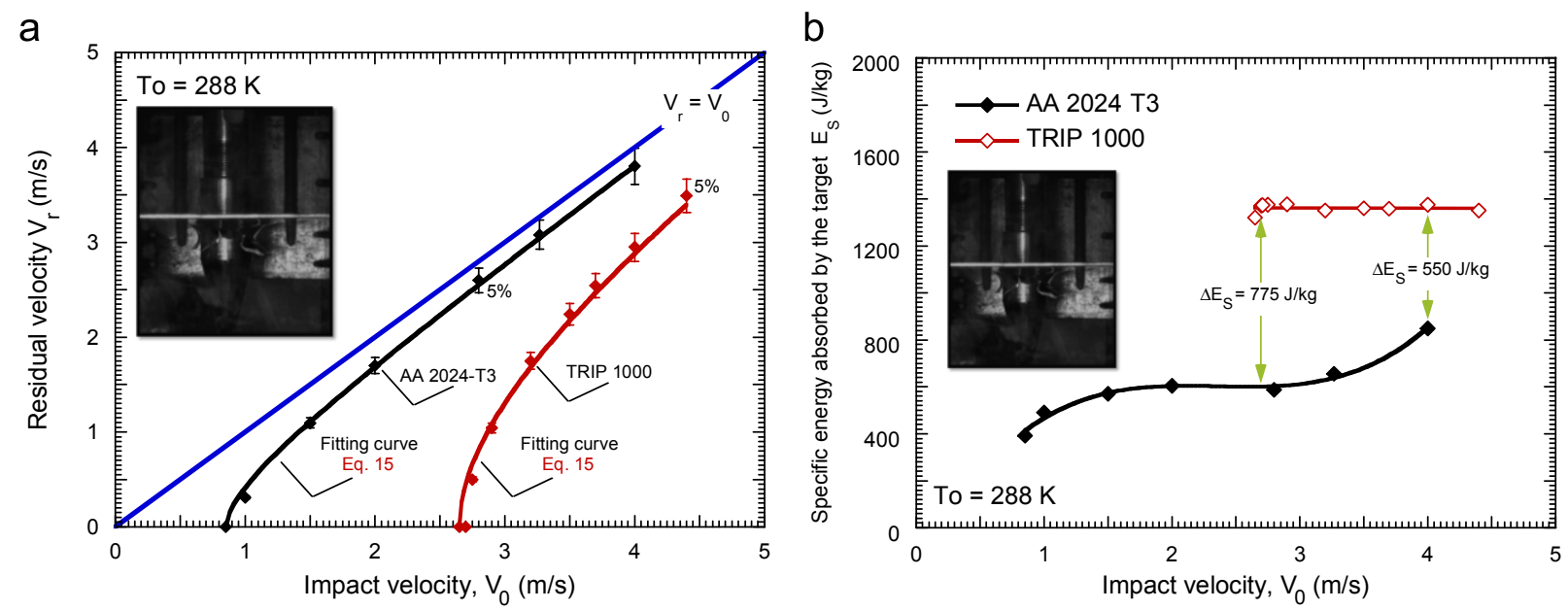

Fig. 14. (a) Residual velocity versus impact velocity at room temperature for AA 2024-T3 and TRIP 1000 sheets [24]. (b) Specific energy absorbed by the plate as a function of the impact velocity for AA 2024-T3 and TRIP 1000 at room temperature [24]. 
testing both metals is identical. This allows a proper comparison of the experimental results obtained for both materials.

\subsection{Tests at room temperature}

First of all the failure mode of the AA 2024-T3 impacted plates is examined. Petalling is the final stage of the perforation process for all the tests performed. Observation of the impacted samples revealed that the number of petals oscillates between four and six for all cases, Fig. 11. It has to be noted that such quantity of petals is frequently reported in the literature [46] for boundary value problems involving perforation of thin plates by conical projec tiles at low/intermediate impact velocities.

Let us explain this recurring number of petals having advantage of the investigations conducted by Wierzbicki [47] and Lee and Wierzbicki [48]. In the mentioned works, based on previous

Table 4

Values of $\kappa$ for both materials tested at $T_{0} 288 \mathrm{~K}$, Eq. (15).

\begin{tabular}{ll}
\hline AA 2024-T3 & TRIP 1000 \\
\hline 1.64 & 1.88 \\
\hline
\end{tabular}

a

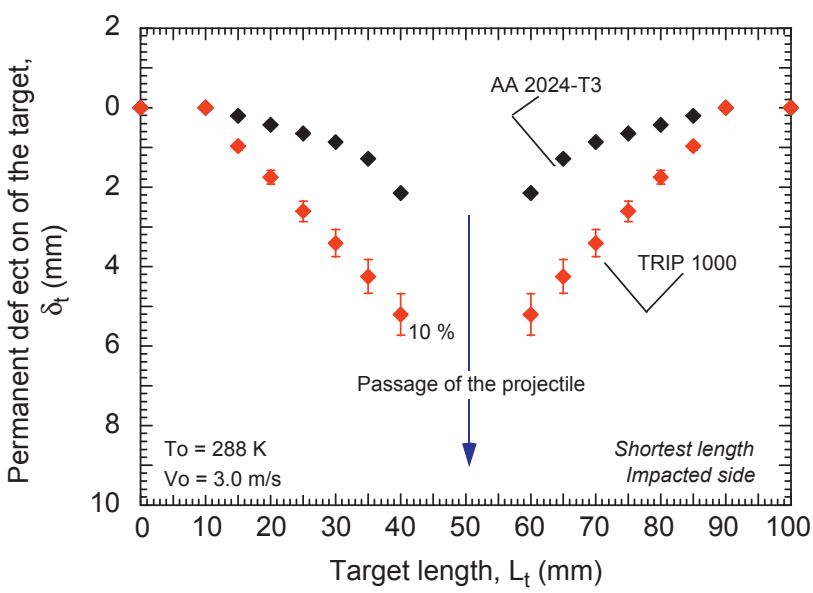

considerations reported by Landkof and Goldsmith [49], the authors proposed an analytical model which considers the energy absorbed by a metallic sheet during perforation as decomposed into plate dishing, crack propagation and petal bending. Such modelling of the mechanical behaviour of metallic plates during perforation allowed deriving the following conclusion; the appearance of a number of petals oscillating between four and six corresponds to a minimum of total rate of energy dissipation. This finding is supported by the experimental observations reported in the present paper. However, it has to be noted that for high/very high impact velocities the perforation mechanisms usually become different and the number of petals is expected to increase as discussed in [50].

Thus, for the boundary value problem discussed, petals forma tion seems to be rather independent of the metal tested. The failure mode of the aluminium sheets coincides with that observed for perforation of TRIP 1000 steel sheets as reported by the authors in a previous work [24], Fig. 12.

In the sequence of images of the failure process depicted in Fig. 13. the perforation mechanisms leading to petalling formation are clearly observed. A dishing phase is found at the beginning of the loading process involving elastic and plastic deflection of the plate, Fig. 13a. Subsequently, strain localises on the contact surface striker/plate leading to the onset of cracks, Fig. 13a. From this point b

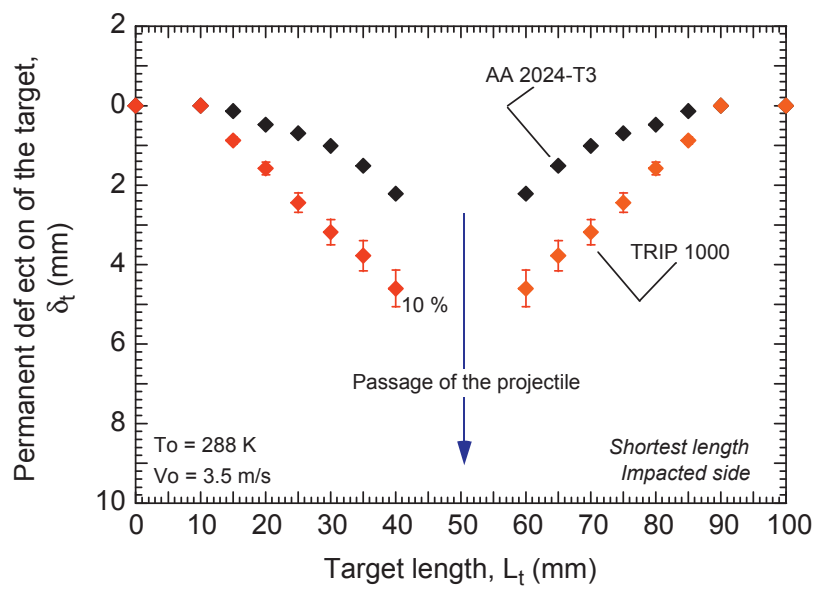

Fig. 15. Permanent deflection of the target for different impact velocities at room temperature. Comparison between AA 2024-T3 and steel TRIP 1000 [24].
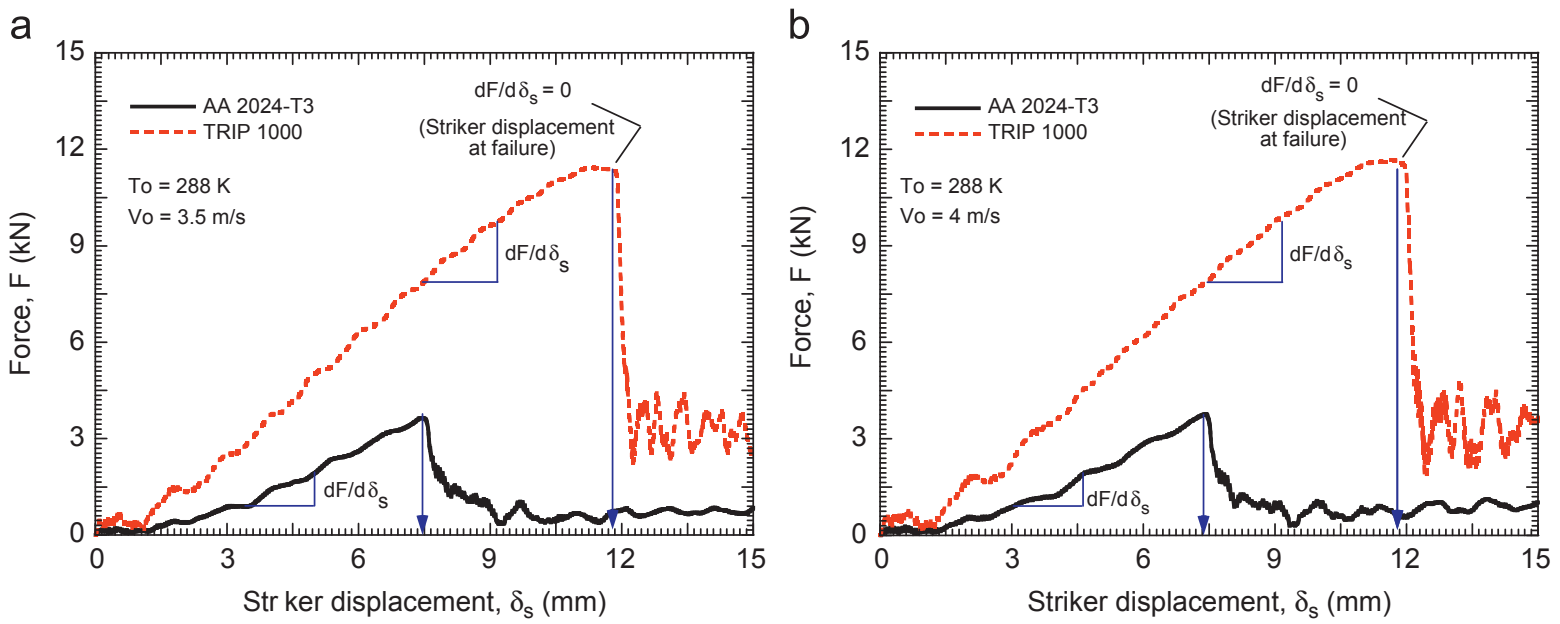

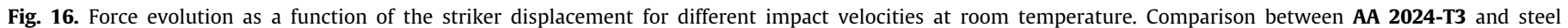
TRIP 1000. 
on, high circumferential strains caused by the passage of the striker lead to radial crack propagation, Fig. 13b. A number of (quasi) symmetric petals are formed and bent until complete perforation of the target Fig. 13c, d. Thus, plastic instabilities formation and progression are revealed responsible for the target collapse in this boundary value problem.

Next, let us illustrate the curve residual velocity/initial velocity obtained from experiments, Fig. 14a. In this figure the residual velocity value, $V_{r}$, is assumed as the speed of the striker corre sponding to the failure time. The failure time, $t_{f}$, is considered as the perforation stage for which the projectile pierces the target and the ballistic limit, $V_{b l}$, is taken as the maximum speed of the striker for which no crack is generated in the plate. The ballistic limit value obtained from the experiments performed at room temperature for the AA 2024-T3 samples is $\left.V_{b 1}\right|_{T_{0}} ^{\mathrm{AA} 2024-\mathrm{T} 3} \approx$ $0.9 \mathrm{~m} / \mathrm{s}$, Fig. 14a, which corresponds to an energy absorbed by the target, Eq. (14). $\left.E_{t}\right|_{V_{b b}, T_{0} 288 \mathrm{~K}} ^{\mathrm{AA} 202 \mathrm{~T} 3}=7.6 \mathrm{~J}$. These values are con siderably lower than those found for perforation of the TRIP 1000

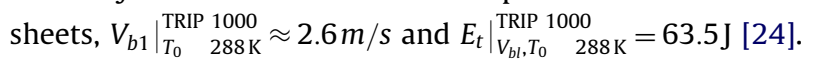

$E_{t}=\frac{1}{2} M_{\text {total }}\left(V_{0}^{2} \quad V_{r}^{2}\right)$

The results shown in Fig. 14a have been fitted via the expression proposed by Recht and Ipson [51]

$V_{r}=\left(\begin{array}{ll}V_{0}^{\kappa} & V_{b l}^{\kappa}\end{array}\right)^{1 / \kappa}, \quad V_{0} \geq V_{b l}$

where $\kappa$ is a fitting parameter. The values of $\kappa$ found for both materials tested are given in Table 4 .

Moreover, let us analyse the evolution of the specific energy absorbed by the target $E_{\mathrm{S}}^{\text {target }}$, Eq. (16), as a function of the impact velocity, Fig. 14b.

$$
E_{\mathrm{S}}^{\mathrm{target}}=\frac{E_{t}}{\rho_{\text {target }} A_{f} h}
$$

It can be observed that the specific energy absorbed by the TRIP 1000 specimens is much larger than that corresponding to the AA 2024-T3 samples. However, it was previously reported that, in regular tensile testing Fig. 3, the AA 2024-T3 samples absorbed slightly larger amount of specific energy than the TRIP 1000 specimens.

Thus, it is necessary to determine the causes responsible for this disagreement. Those causes must reside in the particularities of the perforation problems of metallic sheets.

Thus, the next step is to examine the permanent deflection of the impacted plates for both materials tested, Fig. 15. It has to be noted that, for the boundary value problem studied, plastic deformation in form of bending acts as main mechanism for energy absorption by the target [24,52]. As illustrated in Fig. 15 the AA 2024-T3 sheets show much reduced permanent bending than the TRIP $\mathbf{1 0 0 0}$ sheets for the whole range of impact velocities investigated.

The amount of kinetic energy of the striker converted into plastic work is strongly dependent on the metal considered. During perforation, the strain leading to target failure in the case of the AA 2024-T3 samples is much reduced than in the case of the TRIP 1000 specimens. It seems that local plastic behaviour involving instabilities formation and subsequent failure differs very much for both materials. This observation matches with the conclusions that may be derived from the analysis of the experi mental curves force/striker displacement, Fig. 16.

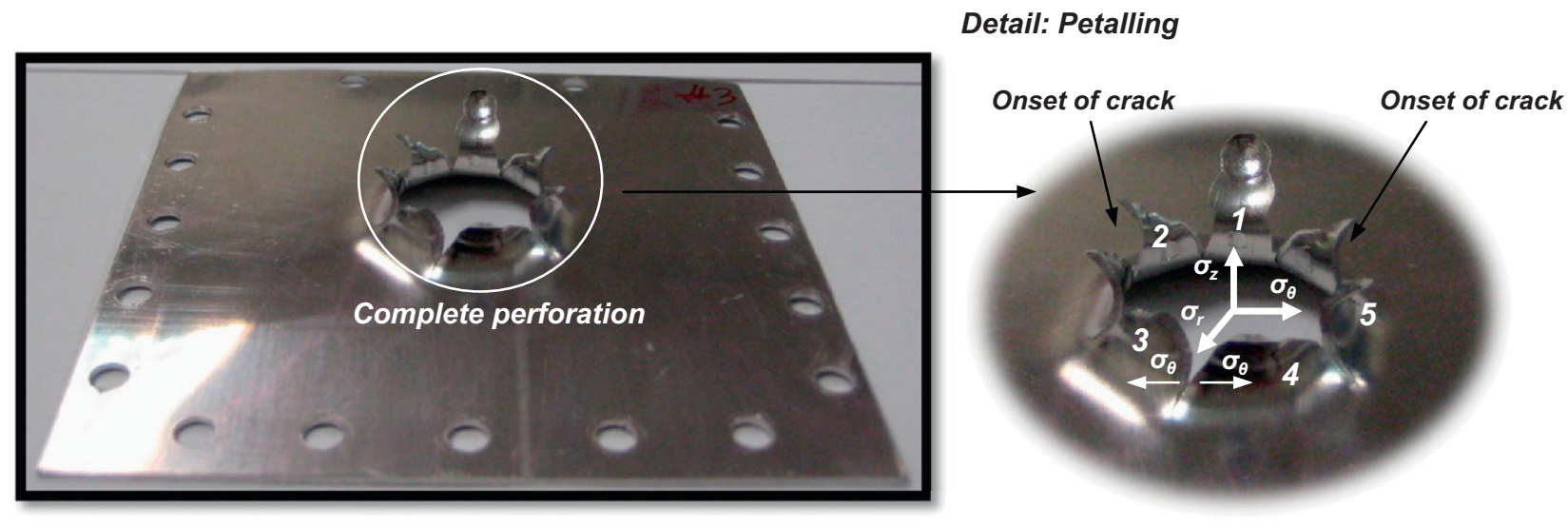

Fig. 17. Petalling failure mode for an AA 2024-T3 sheet, $V_{0} \quad 2.0 \mathrm{~m} / \mathrm{s}$ and $T_{0} 213 \mathrm{~K}$.

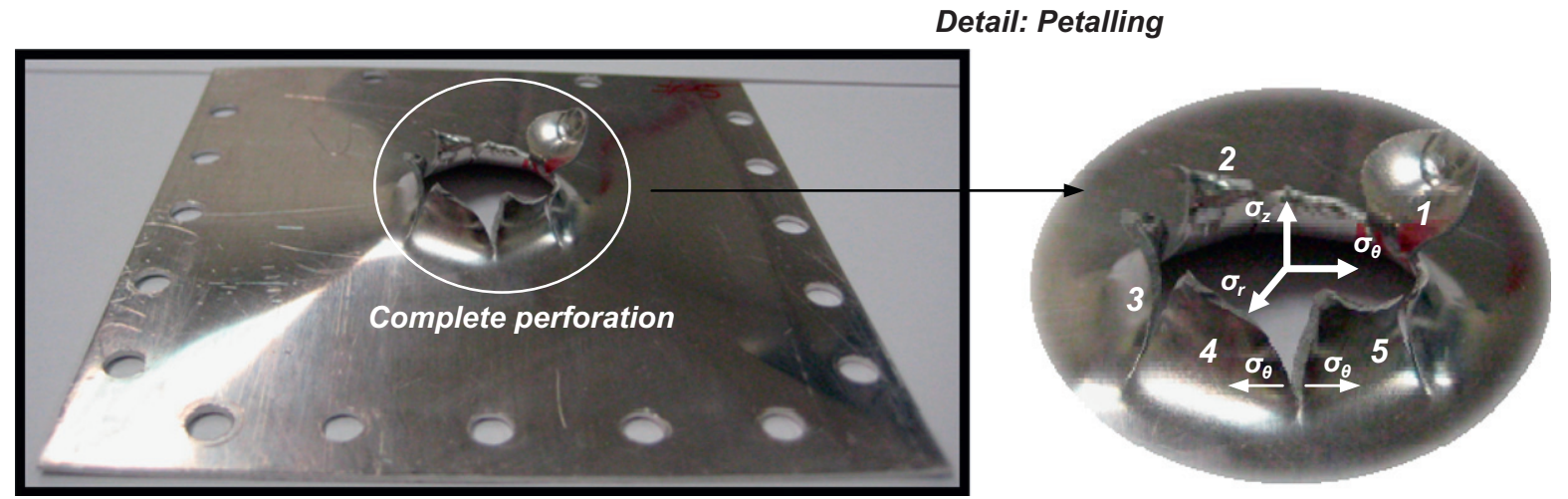

Fig. 18. Petalling failure mode for an AA 2024-T3 sheet, $V_{0} \quad 4.0 \mathrm{~m} / \mathrm{s}$ and $T_{0} \quad 213 \mathrm{~K}$. 
For all the impact velocities considered, in the case of testing the AA 2024-T3 sheets, both the slope of the curve force/striker displacement, $\partial F /\left.\partial \delta_{\mathrm{S}}\right|_{\mathrm{AA2024-T3}}<\partial F /\left.\partial \delta_{\mathrm{S}}\right|_{\text {TRIP 1000, }}$, and the striker displacement at failure, $\left.\delta_{\mathrm{S}}\right|_{\partial \mathrm{F} / \partial \delta_{\mathrm{S}}} ^{\mathrm{AA}-\mathrm{T} 3}<\left.\delta_{\mathrm{S}}\right|_{\partial \mathrm{F} / \partial \delta_{\mathrm{S}} \quad 0} ^{\mathrm{TRI}}$, are much lower than in the case of testing the TRIP 1000 sheets, Fig. 16.

The important difference concerning the slope of the curves force/striker displacement $\partial F / \partial \delta_{\mathrm{S}}$ is easily explained by the higher flow stress level of the TRIP $\mathbf{1 0 0 0}$ in comparison with that corresponding to the AA 2024-T3, Fig. 3.

However, the gap in the striker displacement at failure is greater than that initially expected in view of Fig. 3 (difference in the striker displacement at failure in the perforation tests is in percentage much larger than the difference in ductility depicted in Fig. 3). This behaviour may be explained as follows. As previously mentioned, the collapse of the target was caused by plastic instabilities formation and subsequent onset of cracks. The latter defined in Fig. 16 by the condition $\partial F / \partial \delta_{S}=0$. So, the amount energy absorbed by the target due to plastic work is directly tied to the susceptibility of the material for instabilities formation. According to several authors [53 55], strain localisation is strongly influenced by inertia; increasing material density delays flow localisation.

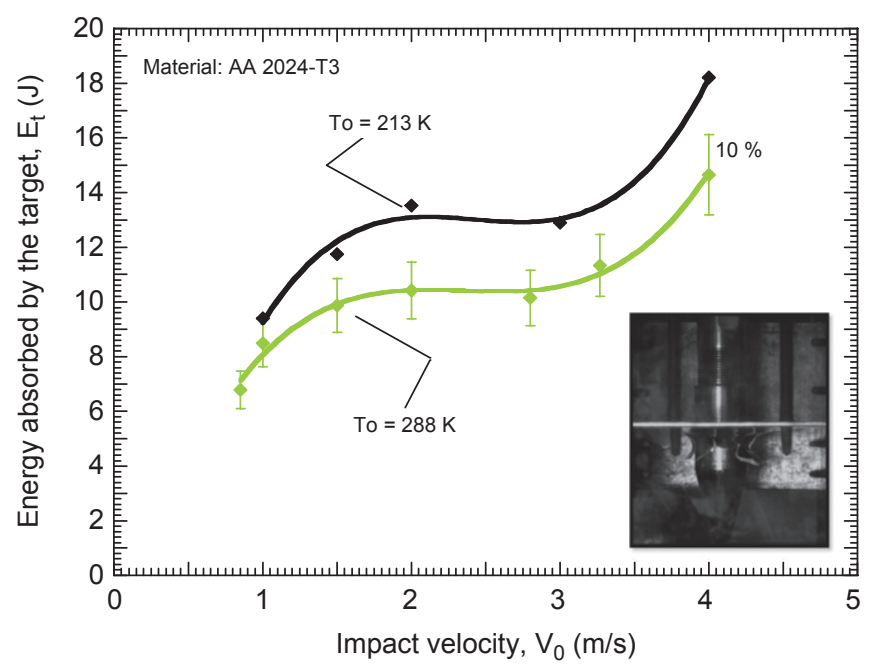

Fig. 19. Energy absorbed by the target as a function of the impact velocity for different initial temperatures.
Supported by previous idea, it is feasible to assume that material density by itself is playing an important role on the energy absorption by the target during perforation. The steel TRIP 1000 seems to have advantage of its larger density to delay plastic instabilities formation. Local plasticity effects controlled (up to a certain point) by inertia seem to determine the ability of the material for energy absorption (quantified in terms of specific energy in Fig. 14b). This conclusion agrees with the considerations reported in [14] concerning the poor performance of thin aluminium plates under impact/perforation (in comparison with thin steels plates).

Thus, it seems that certain High Strength Steels like the TRIP 1000 may be more convenient than determined light weight alloys for building structures responsible for absorbing energy under dynamic solicitations involving plastic instabilities forma tion and failure.

In order to go further in this investigation, perforation tests were conducted at $T_{0}=213 \mathrm{~K}$. Experiments performed at this tempera ture on the AA 2024-T3 samples have special interest due to the application of this material for building aircraft structures.

\subsection{Tests at low temperature}

Before testing at low temperature the aluminium sheets (clamped and screwed) were subjected to $T_{0}=213 \mathrm{~K}$ for $10 \mathrm{~min}$. This period of time is suitable to reach thermal equilibrium material target/testing temperature. High thermal conductivity of aluminium alloys leads to small exposition time for achieving thermal equilibrium with surrounding temperature.

The failure mode of the plates tested at low temperature is analogous to that reported for the tests at room temperature. For the whole range of impact velocities covered, petals formation is the final stage of the perforation process, Figs. 17 and 18.

It is necessary to remark that decreasing the initial temperature the ballistic limit is notably increased $\left.V_{b 1}\right|_{T_{0}} ^{\mathrm{AA} 2024-\mathrm{T} 3 \mathrm{~K}} \approx 0.9 \mathrm{~m} / \mathrm{s} \rightarrow$ $\left.V_{b 1}\right|_{T_{0} 213 \mathrm{~K}} ^{\mathrm{AA} 2024-\mathrm{T} 3} \approx 1.1 \mathrm{~m} / \mathrm{s}$. The energy absorbed by the AA 2024-T3 sheets at $T_{0}=213 \mathrm{~K}$ is $\approx 20 \%$ larger than that absorbed at $T_{0}=288 \mathrm{~K}$ within the whole range of impact velocities tested, Fig. 19. As previously discussed, improved flow stress and strain hardening of this material at low temperature is identified responsible for the good performance of the AA 2024-T3 at $T_{0}=213 \mathrm{~K}$, Fig. 19.

However, the specific energy absorbed by the target is still much greater in the case of testing the TRIP $\mathbf{1 0 0 0}$ samples for the whole range of impact velocities considered, Fig. 20. In Fig. 20a is
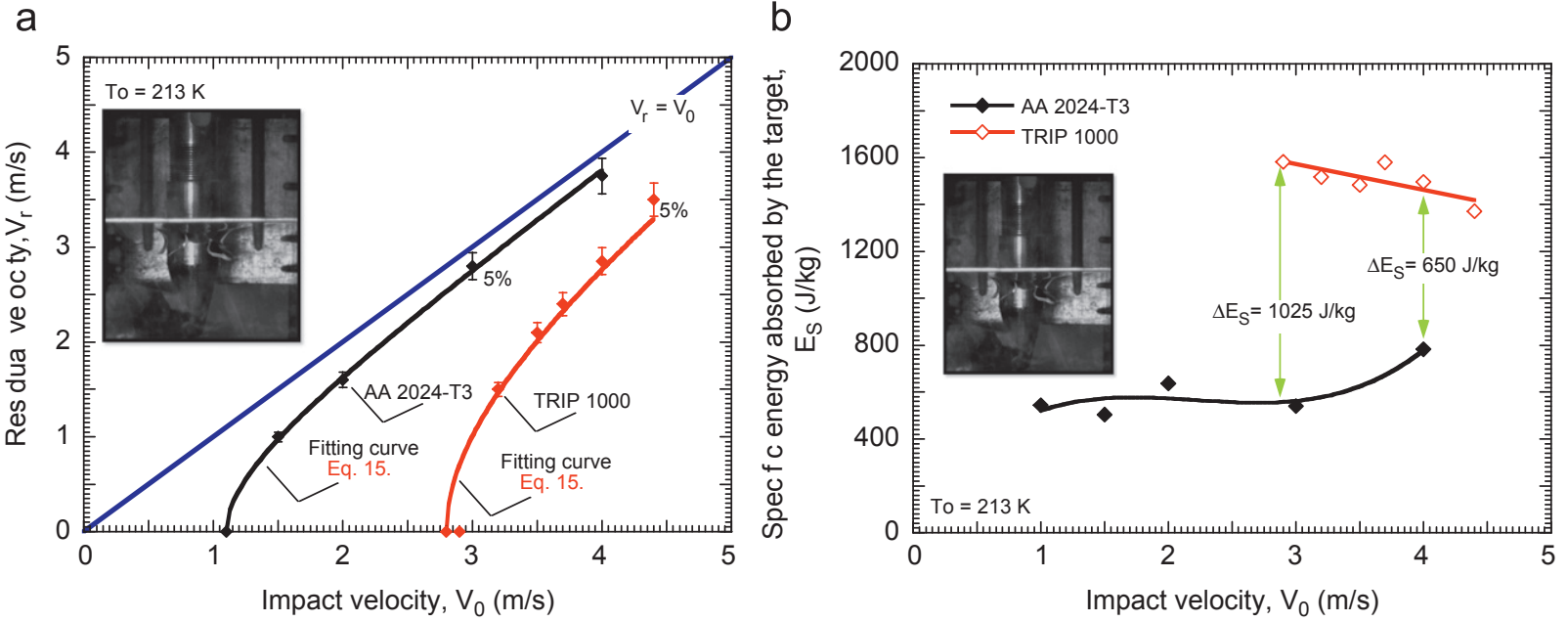

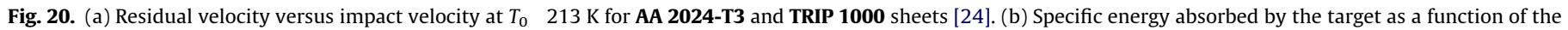
impact velocity at $T_{0} \quad 213 \mathrm{~K}$ for AA 2024-T3 and TRIP 1000 [24]. 
shown the evolution of the residual velocity as a function of the impact velocity for both materials analysed at $T_{0}=213 \mathrm{~K}$. These results obtained from the tests have been fitted via Eq. (15). The values of the fitting parameter $\kappa$ found for both materials tested are given in Table 5 .

Although permanent bending of the AA 2024-T3 samples increases at low temperature enhancing the ability of the material for absorbing energy, Fig. 21; deflection of the aluminium targets is still much lower than deflection of the steel targets, Fig. 22. As discussed for the tests at room temperature, it is assumed that during perforation at $T_{0}=213 \mathrm{~K}$ the local strain leading to instabilities formation is much larger in the case of the TRIP 1000 specimens than in the case of the AA 2024-T3 specimens.

Previous considerations are reflected in the curves force/striker displacement recorded from experiments, Figs. 23 and 24. In the case of testing the aluminium sheets at low temperature the striker displacement at failure augments in comparison with testing at room temperature, Fig. 23. It is clear that the local strain leading to instabilities formation in the AA 2024-T3 samples increases at $T_{0}=213 \mathrm{~K}$ but it is still much reduced than that corresponding to the TRIP 1000 specimens, Fig. 24.

Thus, despite of the improved mechanical properties of the $\mathbf{A A}$ 2024-T3 at $T_{0}=213 \mathrm{~K}$, reduced strain of instability of this material in comparison with that corresponding to the TRIP $\mathbf{1 0 0 0}$ acts as limiting factor for the capability of the aluminium alloy for absorbing energy under perforation. Based on the investigations reported by several authors [53 54] inertia may be identified as potential responsible for such limitation.

Further investigations for evaluation of the ability of light weight structures for energy absorption under dynamic events involving instabilities formation and failure are required. Compara tive studies with High Strength Steels are advisable for that goal.

\section{Concluding remarks}

In this work the mechanical behaviour of the AA 2024-T3 has been examined. The thermo viscoplastic response of the material has been characterised in tension within wide ranges of strain

Table 5

Values of $\kappa$ for both materials tested for $T_{0} 213 \mathrm{~K}$, Eq. (15).

\begin{tabular}{ll}
\hline AA 2024-T3 & TRIP 1000 \\
\hline 1.88 & 1.90 \\
\hline
\end{tabular}

a

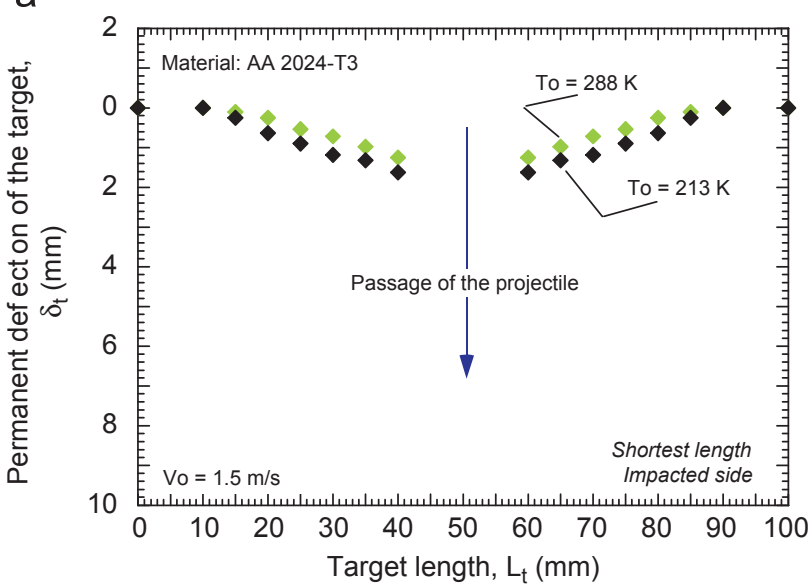

rate and temperature. The MRK constitutive description has been applied for modelling the deformation behaviour of the material and good correlation between experiments and analytical predic tions of the model has been found.

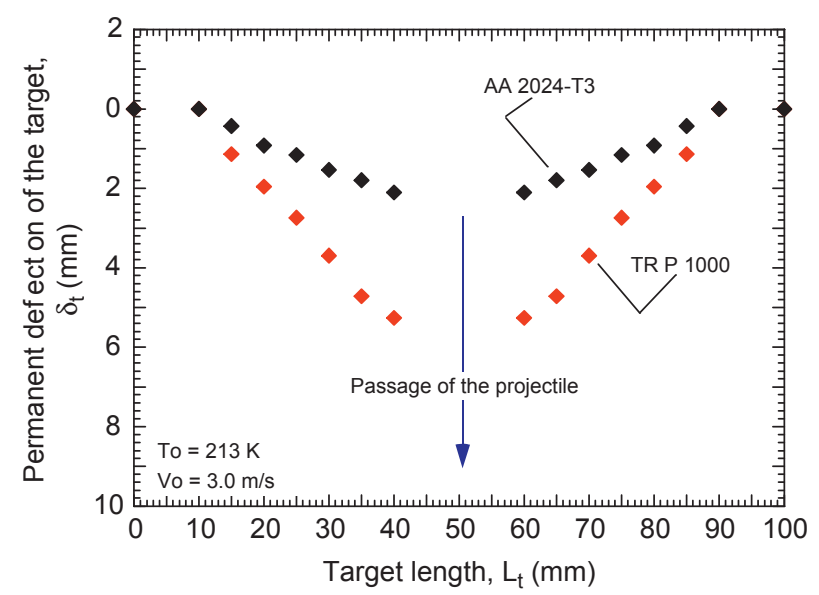

Fig. 22. Permanent deflection of the target for $V_{0} \quad 3.0 \mathrm{~m} / \mathrm{s}$ at $T_{0} \quad 213 \mathrm{~K}$. Comparison between AA 2024-T3 and steel TRIP 1000 sheets [24].

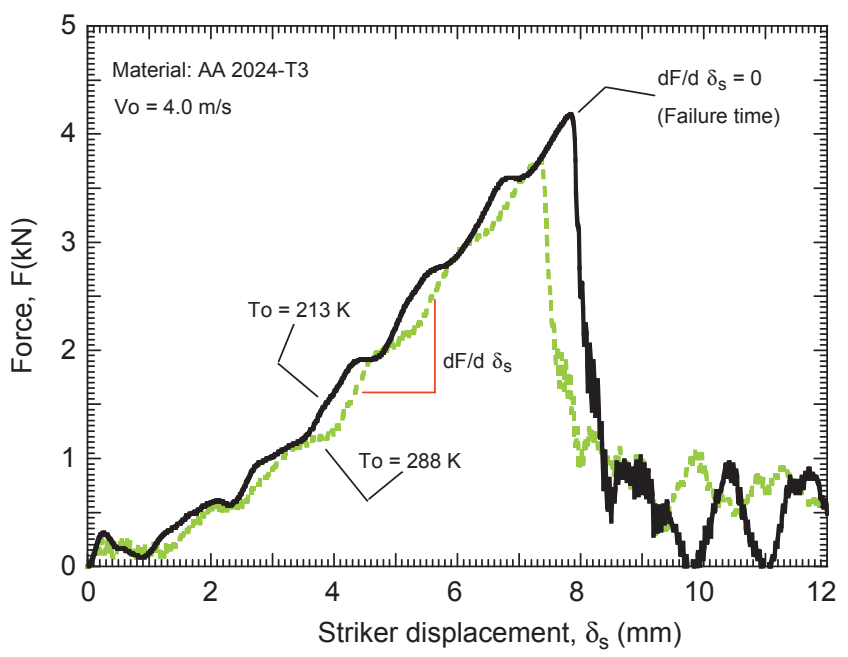

Fig. 23. Force evolution as a function of the striker displacement for an AA 2024-T3 sheet, $V_{0} \quad 4.0 \mathrm{~m} / \mathrm{s}$ and different initial temperatures.

b

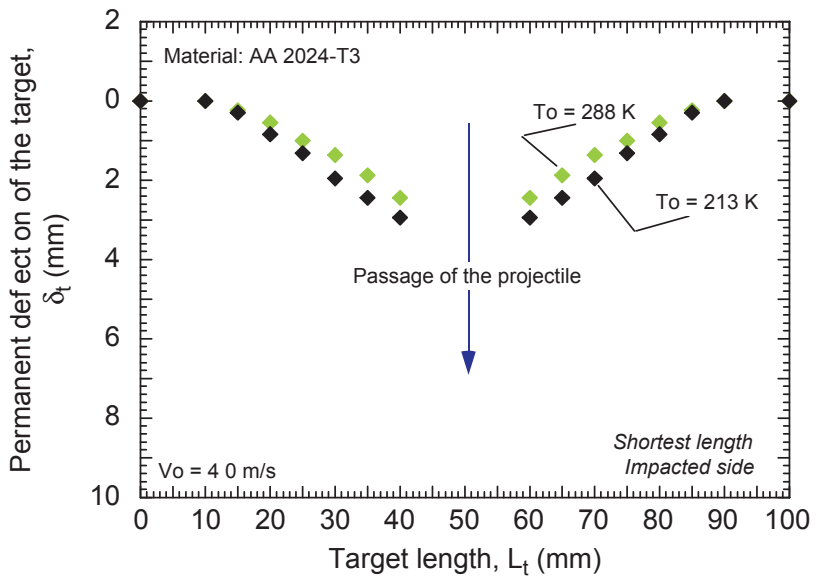

Fig. 21. Permanent deflection of AA 2024-T3 targets for different impact velocities and initial temperatures. 


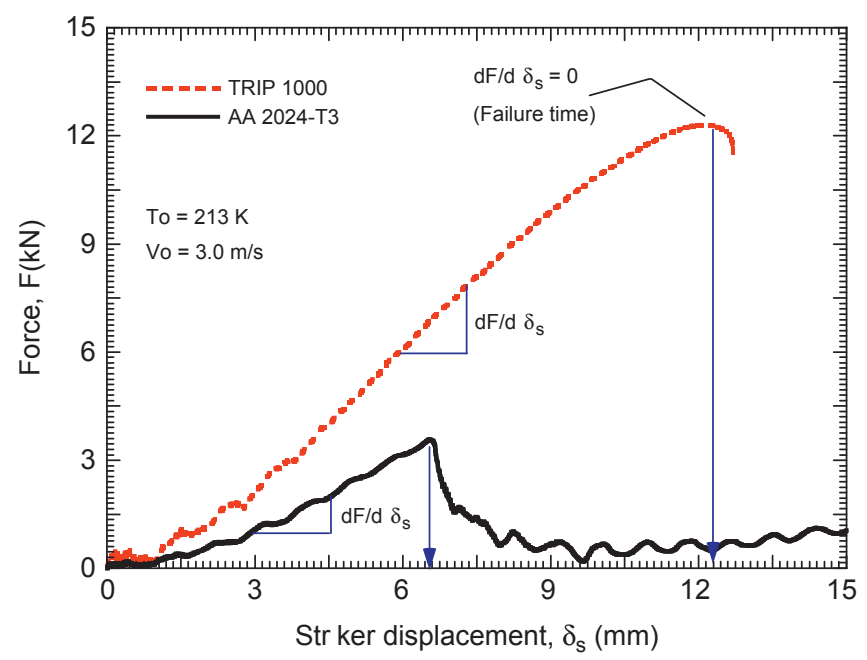

Fig. 24. Force evolution as a function of the striker displacement at $T_{0} 213 \mathrm{~K}$. Comparison between AA 2024-T3 and steel TRIP 1000 sheets [24].

In order to evaluate the suitability of this material for energy absorption under dynamic solicitations low velocity perforation tests at different temperatures have been performed using a drop weight tower. The results from these tests have been compared with those previously published by the authors for steel TRIP 1000. The investigation led to the following main conclusions:

- The AA 2024-T3 improves its capability for energy absorption at low initial temperature (within the range of initial tempera tures tested). Increasing strain hardening of the material as the testing temperature diminishes, enhances ductility of this alloy augmenting the capability of the AA 2024-T3 sheets for converting kinetic energy of the impactor into plastic work.

- The AA 2024-T3 samples absorb quite lower amount of specific energy than that corresponding to the TRIP 1000 steels sheets (for all the perforation conditions tested). The role played by inertia on delaying the target collapse via enhancing material local plasticity (strain of instability) may be deter mined as potential responsible for such behaviour. Such conclusion makes indispensable further investigations dealing with the capability of determined light weight structures for absorbing energy under impact/perforation.

\section{Acknowledgements}

The authors express their thanks to Mr. Jose Puerta and Mr. Sergio Puerta for their technical support.

The authors express their thanks to Mr. Philippe and Mr. Tobisch from the company Zwick for the facilities conferred to perform the tensile tests at high strain rates.

The researchers of the University Carlos III of Madrid are indebted to the Comunidad Autónoma de Madrid (Project CCG08 UC3M/MAT 4464) and to the Ministerio de Ciencia e Innovación de España (Project DPI/2008 06408) for the financial support received which allowed conducting part of this work.

\section{References}

[1] Kumar A, Hauser FE, Dorn JE. Viscous drag on dislocations in aluminum at high strain rates. Acta Metall 1968;9:1189-97.

[2] Nemat-Nasser S, Guo WG, Cheng JY. Mechanical properties and deformation mechanisms of a commercially pure titanium. Acta Mater 1999;47:3705-20.

[3] Nemat-Nasser S, Guo WG, Nesterenko VF, Indrakanti SS, Gu YB. Dynamic response of conventional and hot isostatically pressed $\mathrm{Ti}-6 \mathrm{Al}-4 \mathrm{~V}$ alloys: experiments and modeling. Mech Mat 2001;33:425-39.
[4] Rusinek A, Klepaczko JR. A numerical study on the wave propagation in tensile and perforation test. J Phys IV 2002;10:653-8.

[5] Smerd R, Winkler S, Salisbury C, Worswick M, Lloyd D, Finn M. High strain rate tensile testing of automotive aluminum alloy sheet. Int J Impact Eng 2005;32:541-60.

[6] El-Magd EM, Abouridouane M. Characterization, modelling and simulation of deformation and fracture behaviour of the light-weight wrought alloys under high strain rate loading. Int J Impact Eng 2006;32:741-58.

[7] Rusinek A, Rodríguez-Martínez JA. Thermo-viscoplastic constitutive relation for aluminium alloys, modelling of negative strain rate sensitivity and viscous drag effects. Mater Des 2009;30:4377-90.

[8] Miller WS, Zhuang L, Bottema J, Wittebrood AJ, De Smet P, Haszler A. Recent development in aluminium alloys for the automotive industry. J Mater Sci Eng A 2000;280:37-49.

[9] Piekutowski AJ. Characteristics of debris clouds produced by hypervelocity impact of aluminum spheres with thin aluminum plates. Int J Impact Eng 1993;14:573-86.

[10] Piekutowski AJ. Holes produced in thin aluminium sheets by the hypervelocity impact of aluminium spheres. Int J Impact Eng 1999;23:711-22.

[11] Forrestal MJ, Piekutowski AJ. Penetration experiments with 6061-T6511aluminum targets and spherical-nose steel projectiles at striking velocities between 0.5 and $3.0 \mathrm{~km} / \mathrm{s}$. Int J Impact Eng 2000;24:57-67.

[12] Alavi Nia A, Hoseini GR. Experimental study of perforation of multilayered targets by hemispherical-nosed projectiles. J Mater Design, 2010. 32; 1057-1065.

[13] Borvik T, Clausen AH, Hopperstad OS, Langseth M. Perforation of AA5083-H116 aluminium plates with conical-nose steel projectiles-experimental study. Int J Impact Eng 2004;30:367-84.

[14] Børvik T, Clausen AH, Eriksson M, Berstad T, Hopperstad OS, Langseth M. Experimental and numerical study on the perforation of AA6005-T6 panels. Int. J. Impact Eng 2005;32:35-64.

[15] Grytten F, Børvik T, Hopperstad O, Langseth M. Low velocity perforation of AA5083-H116 aluminium plates. Int J Impact Eng 2009;36:597-610.

[16] Børvik T, Forrestal MJ, Hopperstad OS, Warren TL, Langseth M. Perforation of AA5083-H116 aluminium plates with conical-nose steel projectilescalculations. Int J Impact Eng 2009;36:426-37.

[17] Gupta NK, Iqbal MA, Sekhon GS. Experimental and numerical studies on the behaviour of thin aluminium plates subjected to impact by blunt- and hemispherical-nosed projectiles. Int J Impact Eng 2006;32:1921-44.

[18] Gupta NK, Iqbal MA, Sekhon GS. Effect of projectile nose shape, impact velocity and target thickness on deformation behaviour of aluminium plates. Int J Solids Struct 2007;44:3411-39.

[19] Gupta NK, Iqbal MA, Sekhon GS. Effect of projectile nose shape, impact velocity and target thickness on the deformation behaviour of layered plates. Int J Impact Eng 2008;35:37-60.

[20] Iqbal MA, Chakrabarti A, Beniwal S, Gupta NK. 3D numerical simulations of sharp nosed projectile impact on ductile targets. Int J Impact Eng 2010;2: 185-95.

[21] Iqbal MA, Gupta G, Diwakar A, Gupta NK. Effect of projectile nose shape on the ballistic resistance of ductile targets. Eur J Mech-A/Solids 2010;29: 683-94.

[22] Rusinek A, Rodríguez-Martínez JA, Arias A. A thermo-viscoplastic constitutive model for FCC metals with application to OFHC copper. Int J Mech Sci 2010;52: 120-35.

[23] Clausen AH, Børvik T, Hopperstad OS, Benallal A. Flow and fracture characteristics of aluminium alloy AA5083-H116 as function of strain rate, temperature and triaxiality. Mater Sci Eng A 2004;364:260-72.

[24] Rodríguez-Martínez JA, Pesci R, Rusinek A, Arias A, Zaera R, Pedroche DA. Thermo-mechanical behaviour of TRIP 1000 steel sheets subjected to low velocity perforation by conical projectiles at different temperatures. Int J Solids Struct 2010;47:1268-84.

[25] Rusinek A, Klepaczko JR. Experiments on heat generated during plastic deformation and stored energy for TRIP steels. Mater Des 2009;30:35-48.

[26] Hamada H, Ramakrishna S. Scaling effects in the energy absorption of carbon-fiber/peek composite tubes. Composite Sci Technol 1995;55: 211-21.

[27] Ochelski S, Gotowicki P. Experimental assessment of energy absorption capability of carbon-epoxy and glass-epoxy composites. Composite Struct 2009;87:215-24.

[28] Follansbee PS. High-strain-rate deformation of FCC metals and alloys. Metallurgical Applications of Shock-Wave and High-Strain-Rate Phenomena 1986:451-79.

[29] Regazzoni G, Kocks UF, Follansbee PS. Dislocation kinetics at high strain rates. Acta Metall 1987;12:2865-75.

[30] Seeger A. The mechanism of glide and work-hardening in face centered cubic and hexagonal close-packed metal. Dislocations and mechanical properties of crystals. New York: J. Wiley; 1957.

[31] Zerilli FJ, Armstrong RW. Dislocation-mechanics-based constitutive relations for material dynamics calculations. J Appl Phys 1987;61:1816-25.

[32] Kocks UF. Realistic constitutive relations for metal plasticity. Mater Sci Eng A 2001;317:181-7.

[33] Nemat-Nasser S, Guo WG. Thermomechanical response of DH-36 structural steel over a wide range of strain rates and temperatures. Mech Mater 2003;35: 1023-47. 
[34] Abed FH, Voyiadjis GZ. Plastic deformation modeling of AL-6XN stainless steel at low and high strain rates and temperatures using a combination of bcc and fcc mechanisms of metals. Int J Plasticity 2005;21:1618-39.

[35] Rodríguez-Martínez JA, Rusinek A, Klepaczko JR. Constitutive relation for steels approximating quasi-static and intermediate strain rates at large deformations. Mech Res Com 2009;4:419-27.

[36] Klepaczko JR. A general approach to rate sensitivity and constitutive modeling of FCC and BCC metals. In: Impact: effects of fast transient loadings, Rotterdam, 1998. p. 3-35.

[37] Rusinek A, Rodríguez-Martínez JA, Klepaczko JR, Pecherski RB. Analysis of thermo-visco-plastic behaviour of six high strength steels. J Mater Des 2009;30:1748-61.

[38] Follansbee PS, Kocks UF. A constitutive description of the deformation of copper based on the use of the mechanical threshold stress as an internal state variable. Acta Metall 1988;1:81-93.

[39] Voyiadjis GZ, Abed FH. Microstructural based models for bcc and fcc metals with temperature and strain rate dependency. Mech Mater 2005;37:355-78.

[40] Voyiadjis GZ, Almasri AH. A physically based constitutive model for fcc metals with applications to dynamic hardness. Mech Mater 2008:40:549-63.

[41] Kocks UF, Argon AS, Ashby MF. Thermodynamics and kinetics of slip. In: Chalmers B, Christian JW, Massalski TB, editors. Progress in materials science, vol. 19. Oxford: Pergamon Press; 1975.

[42] Klepaczko JR. Thermally activated flow and strain rate history effects for some polycristalline f .c.c metals. Mater Sci Eng 1975;18:121-35.

[43] Rusinek A, Klepaczko JR. Effect of adiabatic heating in some processes of plastic deformation. Impact Eng Appl 2001; I \& II:541-6.

[44] Oussouaddi O, Klepaczko JR. An analysis of transition from isothermal to adiabatic deformation in the case of a tube under torsion. J Phys IV 1991; Coll. C3(Suppl. III):C3-323 [in French].
[45] Berbenni S, Favier V, Lemoine X, Berveiller N. Micromechanical modelling of the elastic-viscoplastic behaviour of polycrystalline steels having different microstructures. Mater Sci Eng 2004;372:128-36.

[46] Atkins AG, Khan MA, Liu JH. Necking and radial cracking around perforations in thin sheets and normal incidence. Int J Impact Eng 1998;21(7): 521-39.

[47] Wierzbicki T. Petalling of plates under explosive and impact loading. Int J Impact Eng 1999;22:935-54.

[48] Lee YW, Wierzbicki T. Fracture prediction of thin plates under localized impulsive loading. Part II: discing and petalling. Int J Impact Eng 2005;31: 1277-308.

[49] Landkof B, Goldsmith W. Petalling of thin metallic plates during penetration by cylindro-conical projectiles. Int J Solids Struct 1993;21:245-66.

[50] Rusinek A, Rodríguez-Martínez JA, Zaera R, Klepaczko JR, Arias A, Sauvelet C. Experimental and numerical analysis of failure process of mild steel sheets subjected to perpendicular impact by hemispherical projectiles. Int J Impact Eng 2009;36:565-87.

[51] Recht RF, Ipson TW. Ballistic perforation dynamics. J Appl Mech 1963;30: 384-90.

[52] Rodríguez-Martínez JA, Rusinek A, Pesci R. Experimental survey on the behaviour of AISI 304 steel sheets subjected to perforation. Thin Walled Struct, 2010, 48; 966-78.

[53] Rajendran AM, Fyfe IM. Inertia effects on the ductile failure of thin rings. J Appl Mech Trans ASME 1982;49:31-6.

[54] Rusinek A, Zaera R. Finite element simulation of steel ring fragmentation under radial expansion. Int J Impact Eng 2007;34(4):799-822.

[55] Xue Z, Vaziri A, Hutchinson JW. Material aspects of dynamic neck retardation. J Mech Phys Solids 2008;56:93-113. 